\title{
MICU1 modulates MCU ion selectivity and tolerance to manganese stress
}

\author{
AUTHOR LIST \\ Jennifer Wettmarshausen ${ }^{1,2, \#, ~ V a l e r i e ~ G o h ~}{ }^{1,2, \#}$, Utkarsh Tripathi², Anja Leimpek ${ }^{1,2}$, Yiming \\ Cheng $^{1,2}$, Alexandros A. Pittis ${ }^{3,4}$, Toni Gabaldón ${ }^{3,4,5}$, Dejana Mokranjac ${ }^{6}$ and Fabiana \\ Perocchi ${ }^{1,2,7,{ }^{*}}$
}

\section{AFFILIATIONS}

1 Institute for Diabetes and Obesity, Helmholtz Diabetes Center (HDC), Helmholtz Zentrum München and German National Diabetes Center (DZD), 85764 Neuherberg, Germany;

2 Gene Center Munich, Department of Biochemistry, Ludwig-Maximilians Universität München, 81377 Munich, Germany;

3 Bioinformatics and Genomics Programme, Centre for Genomic Regulation (CRG), 08003 Barcelona, Spain;

4 Departament of Ciències Experimentals I de La Salut, Universitat Pompeu Fabra (UPF), 08003 Barcelona, Spain;

${ }^{5}$ Institució Catalana de Recerca i Estudis Avançats (ICREA), 08010 Barcelona, Spain;

6 Biomedical Center Munich - Physiological Chemistry, Ludwig-Maximilians Universität München, 82152 Martinsried, Germany;

${ }^{7}$ Munich Cluster for Systems Neurology, 81377 Munich, Germany.

\section{"Equal contribution}

*Correspondence: fabiana.perocchi@helmholtz-muenchen.de

Lead Contact: Fabiana Perocchi, fabiana.perocchi@helmholtz-muenchen.de 


\section{SUMMARY}

The mitochondrial calcium uniporter is a highly selective ion channel composed of species- and tissue-specific structural and regulatory subunits. However, the contribution of each component to uniporter-mediated activity still remains unclear. Here, we employ an evolutionary and synthetic biology approach to investigate the functional inter-dependence between the poreforming subunit MCU and the EF-hand protein MICU1. Using phylogenetic profiling and genetic complementation analyses, we show that MCU and MICU1 constitute the minimal eukaryotic unit of the uniporter, pointing towards a strong selective pressure behind their co-occurrence. Heterologous reconstitution of MCU-mediated and MICU1-gated mitochondrial calcium entry in vivo in yeast cells demonstrates that MICU1 per se is essential to protect yeast from MCUdependent manganese cytotoxicity. Accordingly, MICU1 deletion significantly sensitizes human HEK-293 cells to manganese-induced stress. Our study identifies a critical role of MICU1 in the regulation of MCU ion selectivity, with potential implications for patients with MICU1 deficiency. 


\section{INTRODUCTION}

Intracellular calcium $\left(\mathrm{Ca}^{2+}\right)$-mediated signaling is an essential and universal mechanism to mediate adaptive physiological responses to a wide variety of environmental and endogenous stimuli, by regulating cell fate, differentiation, proliferation, metabolic flexibility, secretion, and gene expression (Berridge et al., 2000). Mitochondria from several organisms take an active role in the modulation of cytosolic calcium (cyt- $\mathrm{Ca}^{2+}$ ) dynamics. Due to their ability of rapidly and transiently accumulating $\mathrm{Ca}^{2+}$ and coupling it to ATP production (Denton, 2009; McCormack et al., 1990), mitochondria can shape, remodel, and decode intracellular $\mathrm{Ca}^{2+}$ signals and cover the energetic demand of signaling cells (Mammucari et al., 2018). Early studies on the properties of mitochondrial $\mathrm{Ca}^{2+}\left(\mathrm{mt}-\mathrm{Ca}^{2+}\right)$ uptake in several vertebrate species have proposed that an electrophoretic uniporter mechanism is responsible for the transport of $\mathrm{Ca}^{2+}$ through the inner mitochondrial membrane, which makes use of the steep electrochemical gradient generated by the respiratory chain and is sensitive to general inhibitors of $\mathrm{Ca}^{2+}$-permeable ion channels (Carafoli and Lehninger, 1971; Deluca and Engstrom, 1961; Matlib et al., 1998; Vasington et al., 1972; Vasington and Murphy, 1962). This model was later confirmed by direct electrophysiological measurements of $\mathrm{Ca}^{2+}$ currents in single mammalian mitochondria (Fieni et al., 2012; Kirichok et al., 2004) and since then the physiological role of the mitochondrial calcium uniporter has been extensively investigated in many eukaryotic organisms (De Stefani et al., 2016).

Recently, a functional genomics approach combining comparative physiology analyses of mt$\mathrm{Ca}^{2+}$ uptake, whole-genomes sequencing, and mitochondrial proteome mapping, has allowed the discovery of the first peripheral $\mathrm{Ca}^{2+}$-dependent regulator of $\mathrm{mt}^{-\mathrm{Ca}^{2+}}$ uptake (MICU1) (Perocchi et al., 2010) and the transmembrane pore-forming subunit of the mitochondrial calcium uniporter (MCU) (Baughman et al., 2011; De Stefani et al., 2011) in vertebrates and protozoa. Afterwards, several paralogs of MCU and MICU1, including the membrane-spanning dominant-negative regulator MCUB (Raffaello et al., 2013) and tissue-specific EF handcontaining subunits MICU2 and MICU3 (Patron et al., 2014; Patron et al., 2018; Plovanich et al., 2013), as well as the $10 \mathrm{kDa}$ essential MCU interactor EMRE (Sancak et al., 2013), have been identified in Metazoa. Altogether, those proteins represent a toolkit of inhibitory and enhancing effectors of $\mathrm{mt}-\mathrm{Ca}^{2+}$ uptake that fine-tune the activity of mammalian $\mathrm{MCU}$ in response to cell type and tissue-specific $\mathrm{Ca}^{2+}$ dynamics and energy requirements (De Stefani et al., 2016).

Overall, the complex molecular nature of the mammalian uniporter highlights the physiological relevance of achieving great plasticity and selectivity in $\mathrm{Ca}^{2+}$ uptake, by promoting $\mathrm{Ca}^{2+}$ entry over other divalent ions. Due to the presence of a very large driving force for cation influx, the uniporter must, at the same time, limit mt- $\mathrm{Ca}^{2+}$ accumulation when the cell is at rest, to prevent vicious $\mathrm{Ca}^{2+}$ cycling, but rapidly transmit a cyt- $\mathrm{Ca}^{2+}$ rise to the mitochondrial matrix during cell signaling. The highly selective permeability of the uniporter for $\mathrm{Ca}^{2+}$ is thought to derive from the high-affinity binding of the ion to the DXXE motif at the MCU pore (Arduino et al., 2017; Baughman et al., 2011; Cao et al., 2017; Chaudhuri et al., 2013; Oxenoid et al., 2016), whereas both gating and cooperative activation of the uniporter have been attributed to its interaction 
with hetero-oligomers of MICU1 and MICU2 or MICU3 (Csordas et al., 2013; Kamer et al., 2017; Mallilankaraman et al., 2012; Patron et al., 2014; Patron et al., 2018). However, the respective functional and mechanistic roles of those subunits in regulating uniporter activity have been so far investigated in mammalian systems where the interpretation of results is hampered by differences in the degree of gene silencing and tissue-specific protein composition (Murgia and Rizzuto, 2015; Vecellio Reane et al., 2016), stoichiometry and compensatory remodeling (Liu et al., 2016; Paillard et al., 2017) of the channel. Instead, the budding yeast S. cerevisiae represents an ideal testbed for dissecting the functional contribution of each exogenous component of the human uniporter, given that it completely lacks any detectable MCU homolog (Bick et al., 2012; Cheng and Perocchi, 2015) and endogenous $\mathrm{mt}^{-\mathrm{Ca}^{2+}}$ transport activity (Arduino et al., 2017; Carafoli and Lehninger, 1971; Kovacs-Bogdan et al., 2014; Yamamoto et al., 2016), while enabling the facile expression and targeting of human mitochondrial proteins. We and others have recently shown that the co-expression of human MCU and EMRE in yeast is sufficient to regulate the entry of a bolus of $\mathrm{Ca}^{2+}$ into the matrix of isolated mitochondria (Arduino et al., 2017; Kovacs-Bogdan et al., 2014; Yamamoto et al., 2016) with the same biophysical properties as the mammalian uniporter.

Here we employ yeast as a model system to investigate the functional relationship between human MCU and MICU1. Using a comparative genomics approach, we show that MCU and MICU1 constitute the minimal conserved unit of the uniporter throughout eukaryotic evolution, pointing towards a strong selective pressure behind their co-occurrence. We show that heterologous expression of human MCU, EMRE, and MICU1 are sufficient to reconstitute a $\mathrm{Ca}^{2+-r e g u l a t e d ~ a n d ~ u n i p o r t e r-d e p e n d e n t ~ u p t a k e ~ o f ~} \mathrm{Ca}^{2+}$ from the cytosol to the mitochondria of yeast in vivo in response to environmental stimuli. We exploit this new experimental system to investigate MCU-MICU1 genetic interaction by screening for biological conditions whereby the co-occurrence of MCU and MICU1 would provide a selective fitness advantage. We find that MICU1 is per se essential to protect yeast cells from MCU-dependent iron $\left(\mathrm{Fe}^{2+}\right)$ and manganese $\left(\mathrm{Mn}^{2+}\right)$ toxicity, indicating an unanticipated regulatory function in the ion selectivity of the uniporter. We confirm the physiological relevance of our findings in human HEK-293 cells where the knock-out (KO) of MICU1 greatly sensitizes to $\mathrm{Mn}^{2+}$-induced cell death, which we rescue by re-introducing a wild-type (WT) or EF-hands mutant MICU1 as well as by exogenous $\mathrm{Fe}^{2+}$ supplementation. Altogether, our findings highlight a previously unknown regulatory role of MICU1 in MCU ion permeability, with potential implications for MICU1-related human disorders.

\section{RESULTS}

\section{MCU and MICU1 form the minimal eukaryotic unit of the mitochondrial calcium uniporter}

The molecular identification of the mitochondrial calcium uniporter complex, together with the availability of numerous sequenced genomes from diverse taxonomic groups and of genome annotation tools, offers the opportunity to exploit evolutionary genomics approaches to investigate the functional links between members of this channel. Correlated patterns of presence and absence of two or more proteins of the channel across a large number of 
genomes (co-occurrence) may indicate strong evolutionary constrains for their functional interdependence (de Juan et al., 2013). Here, we examined the phylogenetic profiles and predicted mitochondrial co-localization of the two founding members of the uniporter, MCU and MICU1 (Baughman et al., 2011; De Stefani et al., 2011; Perocchi et al., 2010), across 247 fullysequenced eukaryotic species from multiple taxonomic levels at different evolutionary distances, in order to maximize the resolution of coupled evolutionary patterns (Fig 1A; see also https://itol.embl.de/tree/774755176425021526503446) (Cheng and Perocchi, 2015). Similarly to a previous evolutionary analysis across 138 species (Bick et al., 2012), we observed a widespread distribution of MCU homologs in all major eukaryotic groups, present in nearly all Metazoa and Plants, but only in some Protozoa (e.g., Trypanosoma cruzi and Leishmania major) and Fungi (e.g., Neurospora crassa and Aspergillus fumigatus). Specifically, homologs of MCU have been apparently lost in all Apicomplexa (e.g., Plasmodium falciparum), mitochondrial-devoid, single-cell eukaryotes (e.g., Entamoeba histolytica, Giardia lambia, E. cuniculi), and Saccharomycota (e.g., S. cerevisiae, S.pombe, C. glabrata), (see https://itol.embl.de/tree/774755176425021526503446).

Strikingly, the distribution of MICU1 homologs was largely overlapping with that of MCU (Fig 1A), pointing to a strong functional inter-dependence between the two proteins, which we now know to be part of the same complex. However, the existence of organisms within Basidiomycota and Ascomycota fungal clades with just MCU, such as $N$. crassa and $A$. fumigatus (Bick et al., 2012; Prole and Taylor, 2012) suggests that MICU1 can be dispensable

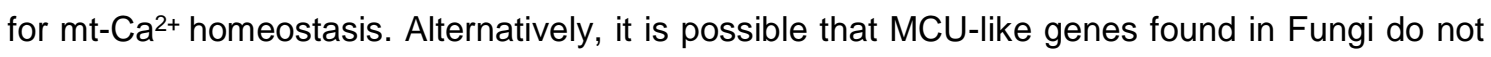
represent functional homologs of the mammalian uniporter. The latter hypothesis is consistent with the observation that human and fungal MCU homologs show very low sequence similarity, which is mainly due to the presence of a generic DUF607 motif and two coiled coil domains (Finn et al., 2016). Furthermore, given the complete loss of EMRE in Fungi (Sancak et al., 2013), fungal MCU homologs should be self-sufficient to drive $\mathrm{mt}^{-\mathrm{Ca}^{2+}}$ uptake, just like the MCU from Dictostillium discoideum (Arduino et al., 2017; Kovacs-Bogdan et al., 2014). Instead, mitochondria from $N$. crassa and $A$. fumigatus were shown to lack $\mathrm{Ca}^{2+}$ uptake activities similar to the fast and high capacity $\mathrm{MCU}$-dependent $\mathrm{Ca}^{2+}$ entry found in mammalian mitochondria (Carafoli and Lehninger, 1971; Gonçalves et al., 2015; Song et al., 2016).

To gain further insights into the functionality of fungal MCU homologs, we tested their ability to complement MCU loss-of-function in human cells. We expressed A. fumigatus (Af-MCU), $N$. crassa (Nc-MCU) or human MCU (Hs-MCU) with a C-terminal V5 tag in MCU knocked-down (shMCU) HeLa cells (Fig 1B). To ensure the targeting of fungal MCUs to human mitochondria, we also tested chimera proteins consisting of the Hs-MCU mitochondrial targeting sequence (HsMTS) fused to the full-length form of Nc-MCU (HsMTSNc-MCU) and Af-MCU (HsMTSAf-MCU). We confirmed that all constructs were enriched in the mitochondria of ShMCU HeLa cells (Fig 1C), similarly to a known mitochondria-localized protein (ATP5A) that was used as a control. Furthermore, all constructs showed proper insertion into the mitochondrial membrane from alkaline carbonate extraction analyses, compared to the integral inner membrane and soluble 
matrix targeted proteins TIM23 and HSP60, respectively (Fig 1D). Next, we quantified mt-Ca ${ }^{2+}$ uptake kinetics upon stimulation with histamine, a $\mathrm{Ca}^{2+}$ activating agonist, which we monitored with the luminescent $\mathrm{Ca}^{2+}$ sensor aequorin stably expressed in the mitochondrial matrix of HeLa cells (mt-AEQ). Although the expression of HsMCU in shMCU HeLa cells resulted in a significant rescue of $\mathrm{mt}^{-\mathrm{Ca}^{2+}}$ level and uptake rate, neither Af-MCU (Fig 1E) nor Nc-MCU (Fig 1F), with and without HsMTS, were able of rescuing the mt-Ca ${ }^{2+}$ uptake phenotype of shMCU HeLa cells.

Collectively, phylogenetic and genetics complementation analyses provide evidence for the lack of a functional human MCU homolog in Fungi (A. fumigatus and N. crassa), and point to another, albeit unknown, function of fungal DUF607-containing proteins. While the possibility of $\mathrm{mt}-\mathrm{Ca}^{2+}$ uptake occurring in other filamentous fungi cannot be excluded, our findings strongly suggest that MCU and MICU1 form the minimal eukaryotic unit of the mitochondrial calcium uniporter.

\section{In vivo reconstitution of mitochondrial calcium uptake in yeast}

We employed the yeast $S$. cerevisiae as a model system to gain insight into the evolutionary pressure behind the tight co-occurrence of MCU and MICU1 across eukaryotic organisms. Yeast is able to maintain its cyt- $\mathrm{Ca}^{2+}$ at sub-micromolar levels, even in the presence of external $\mathrm{Ca}^{2+}$ up to $100 \mathrm{mM}$, and can transiently increase it to activate calcineurin-dependent prosurvival, adaptive transcriptional responses to diverse environmental stresses (Cyert, 2003). We thus asked whether MCU-mediated $\mathrm{mt}^{-\mathrm{Ca}^{2+}}$ uptake could be reconstituted in yeast under physiological conditions that trigger a cyt- $\mathrm{Ca}^{2+}$ burst. To this goal, we tested the ability of HsMCU and Hs-EMRE to reconstitute mt-Ca ${ }^{2+}$ uptake in intact yeast cells in response to stimulusinduced cyt-Ca ${ }^{2+}$ dynamics (Fig 2). As a stimulus we used glucose-induced calcium (GIC) activation (Fig 2A), whereby the addition of a carbon source like glucose to hexoses-starved yeast cells activates a high affinity $\mathrm{Ca}^{2+}$ influx system (HACS) at the plasma membrane and allows the rapid entry of $\mathrm{Ca}^{2+}$ from the extracellular environment (Groppi et al., 2011).

As a first step, we confirmed GIC-dependent activation of cyt- $\mathrm{Ca}^{2+}$ signaling by engineering a yeast strain that expresses a cytosol-localized aequorin (Nakajima-Shimada et al., 1991) and quantified $\mathrm{cyt}^{-\mathrm{Ca}^{2+}}$ kinetics in response to the re-addition of glucose to cells exponentially growing in a non-fermentative medium (Fig 2B). In agreement with previous results (Groppi et al., 2011), we observed that both the amplitude and uptake rate of cyt-Ca ${ }^{2+}$ responses were dependent on the external concentration of $\mathrm{Ca}^{2+}$. Next, we quantified GIC-induced $\mathrm{mt}-\mathrm{Ca}^{2+}$ uptake using a yeast strain that we previously engineered to express mt-AEQ (Arduino et al., 2017). We showed that the heterologous co-expression of WT, full-length Hs-MCU and HsEMRE in yeast is essential to drive $\mathrm{mt}^{-\mathrm{Ca}^{2+}}$ uptake in vivo in response to glucose and in the presence of $1 \mathrm{mM}$ external $\mathrm{Ca}^{2+}$ (Fig 2C). Accordingly, yeast strains expressing Hs-EMRE together with Hs-MCU mutants in highly conserved acidic residues within the DXXE motif (HsMCU ${ }_{D 261 A}$; Hs-MCUE264A) were either partially functional (Hs-MCUD261A) or almost completely unable (Hs-MCU $\left.\mathrm{E}_{264 \mathrm{~A}}\right)$ to fully transfer $\mathrm{GIC}$-induced $\mathrm{cyt}^{-\mathrm{Ca}^{2+}}$ signals into the mitochondrial 
matrix (Fig 2C). Moreover, MCU-mediated $\mathrm{mt}^{-\mathrm{Ca}^{2+}}$ uptake was responsive to a wide dynamic range of external $\mathrm{Ca}^{2+}$ concentrations (Fig 2D) and able to promptly buffer the rise of cyt- $\mathrm{Ca}^{2+}$ induced by glucose at $1 \mathrm{mM}$ extracellular $\mathrm{Ca}^{2+}$ level (Fig 2E).

Afterwards, we tested whether the expression of human MICU1 in the yeast model system would be sufficient to reconstitute a channel that is regulated by $\mathrm{Ca}^{2+}$. We generated a yeast strain expressing Hs-MCU and Hs-EMRE together with either human WT (Hs-MICU1) or EFhands mutant (Hs-MICU1 $1_{\mathrm{mEF}}$ ) MICU1 and showed that those were properly localized to mitochondria (Fig 2F). Notably, the presence of Hs-MICU1 significantly increased MCUdependent $\mathrm{mt}^{-\mathrm{Ca}^{2+}}$ uptake in response to GIC signaling compared to the strain only expressing Hs-MCU and Hs-EMRE, whereas Hs-MICU1meF exerted an inhibitory effect (Fig 2G), as measured by mtAEQ-based light kinetics. To further confirm these results, we also quantified mt-Ca ${ }^{2+}$ buffering capacity in isolated yeast mitochondria using calcium green-5N as a $\mathrm{Ca}^{2+-}$ sensitive fluorescent probe. Consistently with previous results (Yamamoto et al., 2016), measurements of $\mathrm{Ca}^{2+}$ clearance showed that mitochondria from a yeast strain expressing HsMCU, Hs-EMRE and Hs-MICU1 were more efficient in buffering a bolus of high $\mathrm{Ca}^{2+}(100 \mu \mathrm{M})$ from the extramitochondrial space when compared to the same strain without Hs-MICU1 (Fig 2H). As expected, the expression of Hs-MICU1 1 mEF dramatically reduced $\mathrm{mt}_{-} \mathrm{Ca}^{2+}$ uptake, similar to the effect of the MCU inhibitor Ru-360. Altogether, these results are consistent with findings in mammalian cells, where functional MICU1 $\mathrm{Ca}^{2+}$-sensing domains are necessary to activate MCU at high cyt-Ca ${ }^{2+}$ levels (Csordas et al., 2013; Kamer et al., 2017; Mallilankaraman et al., 2012; Patron et al., 2014; Patron et al., 2018).

Finally, our results demonstrate that human MCU and EMRE are sufficient to reconstitute mt$\mathrm{Ca}^{2+}$ uptake in vivo in response to physiological stimuli that trigger cyt- $\mathrm{Ca}^{2+}$ signaling. They also show that the presence of human MICU1 in yeast can regulate $\mathrm{mt}-\mathrm{Ca}^{2+}$ uptake and it is per se sufficient to confer a positive synergistic effect on MCU-mediated $\mathrm{mt}-\mathrm{Ca}^{2+}$ kinetics.

\section{MCU impairs yeast tolerance to iron and manganese stress}

Having reconstituted mammalian-like $\mathrm{mt}-\mathrm{Ca}^{2+}$ signaling in vivo in yeast, we sought to exploit this result to search for biological conditions where the presence of MICU1 would confer a fitness advantage. We hypothesized that a strain expressing only Hs-MCU and Hs-EMRE, which is able to buffer cyt-Ca ${ }^{2+}$ elevations (Fig $2 \mathrm{E}$ ), should be more sensitive to environmental stresses, given that fungal cells need cyt-Ca ${ }^{2+}$ transients to activate pro-survival responses (Cyert, 2003). To test our hypothesis, we compared the fitness of a WT strain to that of yeast strains expressing Hs-EMRE together with either functional (Hs-MCU) or inactive MCU (Hs-MCUE264A) under an array of different environmental conditions, including heat shock, fungicide treatment, high salt and heavy metals stresses (Bultynck et al., 2006; Cyert, 2003; Edlind et al., 2002; Farcasanu et al., 1995; Gupta et al., 2003; Heuck et al., 2010; Nakamura et al., 1993; Pagani et al., 2007; Peiter et al., 2005; Serrano et al., 2004), by employing growth rate as a proxy for cell survival and proliferation (Fig 3). To ensure the reliance of cell proliferation on fully developed and functional mitochondria, all strains were tested during exponential growth in a non- 
fermentable medium, with lactate as a carbon source. Overall, we observed comparable doubling times among the three different strains during normal growth at $30{ }^{\circ} \mathrm{C}$ in lactate medium, which was over two-fold higher upon heat shock $\left(37^{\circ} \mathrm{C}\right)(\mathbf{F i g} 3 \mathrm{~A})$. Likewise, treatment with increasing doses of two antifungal drugs, miconazole and amiodarone, either decreased the growth rate of the yeast cultures by over two-fold (miconazole, $100 \mathrm{ng} / \mathrm{ml}$ ) (Fig 3B) or resulted in a complete cessation of growth (amiodarone, $20 \mu \mathrm{M}$ ) (Fig 3C), independent of the genetic background. All three strains also showed similar sensitivities to high-salt stress when grown under increasing concentration of $\mathrm{NaCl}$ (Fig 3D).

Instead, we observed notable different responses among strains to heavy metals-induced stress $\left(\mathrm{Sr}^{2+}, \mathrm{Cu}^{2+}, \mathrm{Zn}^{2+}, \mathrm{Fe}^{2+}, \mathrm{Mn}^{2+}\right)$ (Fig 3E). Although minimal levels of those cations are important for normal metabolism, high concentrations can be toxic (Farcasanu et al., 1995; Heuck et al., 2010; Pagani et al., 2007; Peiter et al., 2005; Serrano et al., 2004). Accordingly, at extracellular concentrations of $\mathrm{CuCl}_{2}$ and $\mathrm{ZnCl}_{2}$ above 10 and $30 \mathrm{mM}$, respectively, the doubling time of yeast cultures was over two-fold higher, with the exception of $\mathrm{Sr}^{2+}$, for which concentrations above $50 \mathrm{mM}$ could not be tested due to precipitation in the liquid medium. However, while these three strains did not show any significant difference in their tolerance to those cations, we observed a greater hypersensitivity of the functional MCU-reconstituted strain to both $\mathrm{Fe}^{2+}$ and $\mathrm{Mn}^{2+}$ toxicity, which manifested with a drastic reduction in cell proliferation at concentrations

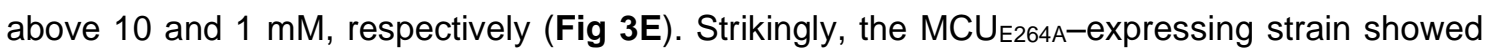
the same tolerance as the WT strain to $\mathrm{Mn}^{2+}$, whereas tolerance to $\mathrm{Fe}^{2+}$ was independent of a functional DXXE motif.

Altogether, these results confute our initial hypothesis that the reconstitution of MCU-dependent mt- $\mathrm{Ca}^{2+}$ buffering in yeast would increase yeast susceptibility to environmental stresses by antagonizing $\mathrm{Ca}^{2+-}$ dependent calcineurin signal transduction cascades, given that the latter is a common link in all tested stress conditions. Instead, our results indicate that the differences in growth rate observed between WT and MCU-reconstituted yeast strains at high extracellular $\mathrm{Fe}^{2+}$ and $\mathrm{Mn}^{2+}$ levels could be due to the known permeability of $\mathrm{MCU}$ to those cations (Ernster, 1978; Hillered et al., 1983; Hughes and Exton, 1983; Medvedeva and Weiss, 2014; Mela and Chance, 1968; Romslo and Flatmark, 1973; Saris, 2012; Saris and Kaija, 1994; Vainio et al., 1970; Vinogradov and Scarpa, 1973), whose accumulation in mitochondria is known to trigger cell death (Smith et al., 2017; Sripetchwandee et al., 2014). Furthermore, whereas our findings corroborate previous evidence of $\mathrm{Mn}^{2+}$ binding and conductance by MCU (Cao et al., 2017), they suggest that the DXXE motif confers selectivity to some but not all cations.

\section{MICU1 protects yeast and human cells from MCU-dependent manganese toxicity}

Given the dramatic reduction of yeast tolerance to $\mathrm{Mn}^{2+}$ stress in the presence of Hs-MCU, we tested whether the reconstitution of a Hs-MICU1 regulated uniporter could rescue this phenotype (Fig 4). Strikingly, the expression of either WT or EF-hands mutant MICU1 significantly rescued the hypersensitivity of the Hs-MCU and Hs-EMRE reconstituted strain towards $\mathrm{Fe}^{2+}$ (Fig 4A) and $\mathrm{Mn}^{2+}$ (Fig 4B) stress. These results indicate that the interaction of 
Hs-MICU1 with Hs-MCU and Hs-EMRE, but not its EF-hands, is sufficient to prevent both $\mathrm{Fe}^{2+}$ and $\mathrm{Mn}^{2+}$ accumulation into the mitochondrial matrix, perhaps by keeping the channel in a close conformation. We then sought to determine whether our findings of a MCU-mediated toxicity and MICU1-dependent protection towards $\mathrm{Fe}^{2+}$ and $\mathrm{Mn}^{2+}$ stress observed in yeast cells would be recapitulated in mammalian cells. To this goal, we compared the viability of WT and MICU1 knockout (MICU1-KO) HEK-293 cells upon treatment with increasing concentrations of either $\mathrm{FeCl}_{2}$ (Fig 4C) or $\mathrm{MnCl}_{2}$ (Fig 4D) for 48 hours. Contrary to yeast cells, the absence of MICU1 did not sensitise cells to $\mathrm{Fe}^{2+}$ stress, as there was no difference in the viability of WT and MICU1-KO cells. Instead, we found a significant increase of cell death in MICU1-KO cells treated with concentrations of $\mathrm{MnCl}_{2}$ that are not lethal to WT cells. As observed in yeast, the protective role of MICU1 towards $\mathrm{Mn}^{2+}$ toxicity was not dependent on having functional $\mathrm{Ca}^{2+}$ sensing domains, as the stable re-introduction of both WT and EF-hands mutant MICU1 in

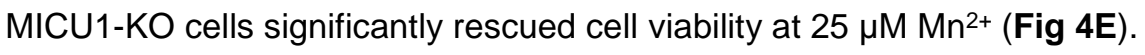

The above observations suggest that patients with MICU1 loss-of-function mutations (LewisSmith et al., 2016; Logan et al., 2014; Musa et al., 2018) might be more susceptible to accumulate $\mathrm{Mn}^{2+}$ in mitochondria, with potentially toxic effects (O'Neal and Zheng, 2015). We thus looked for strategies to ameliorate $\mathrm{Mn}^{2+}$ toxicity in MICU1-KO cells. Although the mechanism of mitochondrial $\mathrm{Mn}^{2+}$ toxicity is not entirely understood, it is believed that the major effect is oxidative stress, resulting in the induction of cell death (Smith et al., 2017). However, we could not detect a significant improvement in the viability of MICU1-KO cells exposed to high $\mathrm{Mn}^{2+}$ in the presence of $0.1 \mu \mathrm{M}$ idebenone (Fig $\mathbf{4 F}$ ), a clinically approved antioxidant drug used in mitochondrial OXPHOS disorders (Holzerova et al., 2016). As an alternative strategy, we cotreated MICU1-KO cells with $\mathrm{Mn}^{2+}$ in presence of $0.5 \mathrm{mM}$ extracellular $\mathrm{FeCl}_{2}$ (Fig $4 \mathbf{G}$ ), as both $\mathrm{Fe}^{2+}$ and $\mathrm{Mn}^{2+}$ compete for entry into cells via the divalent metal transporter 1 (DNM1) (Gunshin et al., 1997) and $\mathrm{Fe}^{2+}$ supplementation has been already shown to reduce $\mathrm{Mn}^{2+}$ overload and toxicity (O'Neal and Zheng, 2015; Tai et al., 2016). Consistently, we observed that the tolerance of MICU1-KO cells to $\mathrm{Mn}^{2}$ stress was completely restored, whereas pre-treatment with the same concentration of $\mathrm{FeCl}_{2}$ for $24 \mathrm{~h}$ was ineffective $(\mathbf{F i g ~} \mathbf{4 H})$. The latter confirms that the protective effect of $\mathrm{Fe}^{2+}$ supplementation results from reducing $\mathrm{Mn}^{2+}$ entry into the cell (O'Neal and Zheng, 2015; Tai et al., 2016).

In summary, these results establish a new functional role of MICU1 in conferring ion selectivity to the uniporter channel, which is independent of the EF-hands, but essential for preventing $\mathrm{Mn}^{2+}$ toxicity, with possible implications for patients with MICU1 deficiency.

\section{DISCUSSION}

Our phylogenetic analyses, as well as a previous comparative genomics study (Bick et al., 2012), have highlighted a widespread co-occurrence of MCU and MICU1 across Metazoa, Plants and Protozoa, with the exception of Fungi. The presence of MCU homologs in several Ascomycota and Basidiomycota fungal clades devoid of a detectable MICU1, together with the 
absence of EF-hands containing proteins co-evolving with fungal MCUs (Cheng and Perocchi, 2015) and the existence of a MCU homolog that is sufficient to drive $\mathrm{Ca}^{2+}$ uptake in mitochondria of $D$. discoideum (Kovacs-Bogdan et al., 2014), led to the hypothesis that MCU could exist independently of a $\mathrm{Ca}^{2+}$-sensing regulator. However, this hypothesis stems from the assumption that fungal MCU homologs per se are able to mediate $\mathrm{mt}^{-\mathrm{Ca}^{2+}}$ uptake. Our results confute this hypothesis by demonstrating that fungal MCUs are not functional homologs of human MCU, given that they cannot complement the loss of uniporter-dependent $\mathrm{Ca}^{2+}$ uptake in mitochondria of MCU knockdown human cells (Fig 1). In light of these findings and previous evidence for the lack of a mammalian-like $\mathrm{mt}-\mathrm{Ca}^{2+}$ uptake in filamentous fungi such as $N$. crassa and A. fumigatus (Carafoli and Lehninger, 1971; Gonçalves et al., 2015; Song et al., 2016), we propose that MCU and MICU1 constitute the minimal functional unit of the eukaryotic uniporter, and speculate that a strong selective pressure must have ensured their functional interdependence.

To investigate the direct contribution of MICU1 on MCU function, we employed the yeast $S$. cerevisiae as a model system, which lacks homologs of all mammalian uniporter components (Bick et al., 2012; Cheng and Perocchi, 2015), as well as endogenous mt-Ca ${ }^{2+}$ uptake activity (Arduino et al., 2017; Carafoli and Lehninger, 1971; Kovacs-Bogdan et al., 2014; Yamamoto et al., 2016). Previous results, including ours, have shown that Hs-MCU and Hs-EMRE are sufficient to drive $\mathrm{Ca}^{2+}$ uptake in vitro into the matrix of isolated mitochondria (Arduino et al., 2017; Kovacs-Bogdan et al., 2014; Yamamoto et al., 2016). While those analyses have corroborated the role of $\mathrm{MCU}$ as the bona fide pore-forming subunit of the uniporter, they did not assess its relevance for the efficient transfer of physiological $\mathrm{Ca}^{2+}$ transients from the cytosol to the mitochondrial matrix of yeast in vivo during signaling. We demonstrate that the heterologous expression of human MCU and EMRE can reconstitute mt-Ca ${ }^{2+}$ entry in vivo in yeast in response to a physiological rise in cyt-Ca ${ }^{2+}$ (Fig 2) and, similar to mammalian cells, the expression of human MICU1 in MCU-reconstituted yeast cells exerts a synergistic effect on mt$\mathrm{Ca}^{2+}$ uptake kinetics, which is dependent on its $\mathrm{Ca}^{2+}$-sensing domains. Next, we searched for biological conditions whereby a positive MCU-MICU1 genetic interaction would provide a selective fitness advantage over a yeast strain reconstituted with MCU without its regulator. To this goal, we investigated the susceptibility of the MCU-expressing yeast strain to an array of stress conditions that require cyt- $\mathrm{Ca}^{2+}$ signaling for survival, including heat shock, salt, heavy metals- and fungicides-induced stresses (Fig 3). Surprisingly, we found that reconstitution of $\mathrm{mtCa}^{2+}$ uptake in yeast did not lead to a fitness disadvantage under standard non-fermentable growth conditions, but it was synthetically lethal with growth in the presence of high $\mathrm{Mn}^{2+}$ and $\mathrm{Fe}^{2+}$ concentrations in the extracellular medium.

The increased susceptibility of MCU-reconstituted yeast cells to $\mathrm{Mn}^{2+}$ and $\mathrm{Fe}^{2+}$ stresses is likely due to the permeation of those ions across the uniporter channel, which has been extensively documented (Ernster, 1978; Hillered et al., 1983; Hughes and Exton, 1983; Mela and Chance, 1968; Romslo and Flatmark, 1973; Saris, 2012; Saris and Kaija, 1994; Sripetchwandee et al., 2014; Vainio et al., 1970; Vinogradov and Scarpa, 1973), leading to their accumulation in 
mitochondria and the consequent toxicity (Smith et al., 2017; Sripetchwandee et al., 2014). This is consistent with the observation that the carboxylate rings formed by the $D$ and $E$ amino acids of the DXXE motif can bind $\mathrm{Mn}^{2+}$ in a cooperative and specific manner even in the presence of $\mathrm{Ca}^{2+}$ (Cao et al., 2017). Although, the direct interaction of other cations, such as $\mathrm{Fe}^{2+}$, with the selectivity filter of MCU has not yet been explored, our results indicate that at least the $E$ of the DXXE motif is dispensable for MCU-mediated $\mathrm{Fe}^{2+}$ entry. Instead, we found that the presence of MICU1 in the MCU-reconstituted strain is sufficient to protect yeast cells against uniporterdependent $\mathrm{Mn}^{2+}$ and $\mathrm{Fe}^{2+-i n d u c e d}$ toxicity (Fig 4). These findings were recapitulated in mammalian cells, where the knockout of MICU1 hypersensitized HEK-293 cells to $\mathrm{Mn}^{2+}$ dependent cell death. Here, $\mathrm{Fe}^{2+}$ treatment did not affect the cell viability of either MICU1-KO or WT cells, even at high non-physiological concentrations, suggesting that the absence of MICU1 is not sufficient to alter $\mathrm{Fe}^{2+}$ homeostasis in mammalian cells, where additional regulatory mechanisms might be in place to prevent cellular $\mathrm{Fe}^{2+}$ overload (Philpott, 2012). Notably, we found that functional MICU1 EF-hands were dispensable to confer protection against $\mathrm{Mn}^{2+}$ cytotoxicity, in contrast to their key role in enhancing $\mathrm{Ca}^{2+}$ uptake in response to a cyt- $\mathrm{Ca}^{2+}$ concentration above threshold (Csordas et al., 2013; Kamer et al., 2017; Mallilankaraman et al., 2012; Patron et al., 2014; Patron et al., 2018). Indeed, the $\mathrm{Mn}^{2+}$-induced toxicity observed in both MICU1-KO HEK-293 cells and MCU-reconstituted yeast strain was ameliorated by a stable expression of either WT or EF-hands mutant MICU1. This suggests that either $\mathrm{Mn}^{2+}$ does not target MICU1 EF-hands or its binding does not trigger the same conformational change that is elicited by $\mathrm{Ca}^{2+}$. The latter is consistent with previous studies demonstrating that $\mathrm{Mn}^{2+}$ can bind EF-hands without eliciting any protein conformational change, confirming their role also for ion selectivity, in addition to ion channel gating (Senguen and Grabarek, 2012; Shirran and Barran, 2009). Altogether, those results demonstrate that MICU1 is an important modulator of the ion selectivity of the mitochondrial calcium uniporter.

Several patients with loss-of-function mutations in MICU1 have been identified over the last few years, displaying a mixture of neurological and myopathic defects (Lewis-Smith et al., 2016; Logan et al., 2014; Musa et al., 2018), which were also recapitulated in MICU1-KO mice (Antony et al., 2016; Liu et al., 2016). Altogether, the disease phenotypes were attributed to a high basal mitochondrial $\mathrm{Ca}^{2+}$ level, possibly due to the loss of MICU1-dependent gatekeeping of the uniporter. Our results would now suggest that the increase in basal mt-Ca ${ }^{2+}$ level upon MICU1 loss-of-function could also result from the loss of MICU1-mediated protection towards $\mathrm{Mn}^{2+}$ entry into mitochondria. The latter would have a two-fold effect on $\mathrm{mt}-\mathrm{Ca}^{2+}$ level and cell viability. First, $\mathrm{Mn}^{2+}$ accumulation into mitochondria is known to inhibit both the $\mathrm{Na}^{+}$-dependent and $\mathrm{Na}^{+}$-independent mitochondrial $\mathrm{Ca}^{2+}$ efflux routes (Gavin et al., 1990). Second, $\mathrm{Mn}^{2+}$ can block the uptake of $\mathrm{Ca}^{2+}, \mathrm{Sr}^{2+}$ and $\mathrm{Ba}^{2+}$, whereas pretreatment of mitochondria with $\mathrm{Ca}^{2+}$ increases the uptake of $\mathrm{Mn}^{2+}$ (Ernster, 1978; Hillered et al., 1983; Hughes and Exton, 1983; Mela and Chance, 1968; Vainio et al., 1970; Vinogradov and Scarpa, 1973). Last, while low doses of $\mathrm{Mn}^{2+}$ are necessary for normal cell and mitochondrial physiology, their accumulation is neurotoxic (Smith et al., 2017). Humans are often exposed to environmental sources of $\mathrm{Mn}^{2+}$, for example by consuming $\mathrm{Mn}^{2+-}$-rich food such as grain products and vegetables, or by 
exposure to $\mathrm{Mn}^{2+}$ aerosols and dusts in mines, smelters, or simply to air pollution from the combustion of gasoline containing methylcyclopentadienyl manganese tricarbonyl (O'Neal and Zheng, 2015). Currently, adjuvant treatments include a dietary restriction of daily $\mathrm{Mn}^{2+}$ intake as well as $\mathrm{Fe}^{2+}$ supplementation (O'Neal and Zheng, 2015). Indeed, we also observed that cotreatment of $\mathrm{Mn}^{2+}$-stressed MICU1-KO cells with $\mathrm{Fe}^{2+}$ was able to prevent $\mathrm{Mn}^{2+}$ cytotoxicity in a dose-dependent manner, whereas pre-treatment with $\mathrm{Fe}^{2+}$, even at high doses, was without any effects. It can be speculated that human mutations in MICU1, that are loss of function for the protein activity, also affect $\mathrm{MCU}$ permeability to the heavy metals, and to $\mathrm{Mn}^{2+}$ in particular. Whether this altered ion permeability contributes to the phenotype of the patients remains to be demonstrated.

In summary, our study demonstrates the power of combining comparative genomics analyses with the use of yeast as a model system for dissecting the functional and mechanistic role of each component of the mammalian uniporter. Moreover, our reconstitution of a MICU1regulated uniporter in yeast offers an incomparable advantage over similar investigation of MICU1 and MCU inter-dependence in mammalian cells, where MICU1 knockout or knockdown has also confounding effects on the expression of other uniporter subunits, such as MICU2 and MICU3 (Patron et al., 2014; Patron et al., 2018; Plovanich et al., 2013). Altogether, our results indicate that MICU1 is not only required for coupling $\mathrm{mt}-\mathrm{Ca}^{2+}$ entry to changes in cyt- $\mathrm{Ca}^{2+}$ concentrations, but it also regulates the uniporter selective gating to $\mathrm{Ca}^{2+}$ ions, with important implications for patients with MICU1 deficiency.

\section{EXPERIMENTAL PROCEDURES}

Additional details and resources used in this work can be found in Supplemental Experimental Procedures.

\section{Phylogenetic Profiling}

The phylogenetic profiles of MCU and MICU1 across 247 eukaryotic species were generated using ProtPhylo (www.protphylo.org) (Cheng and Perocchi, 2015). Protein sequences of Homo sapiens MCU (Hs-MCU, NP_612366.1) Neurospora crassa MCU (Nc-MCU, XP_959658.1), and Aspergillus fumigatus MCU (Af-MCU, XP_751795.1) were analyzed to predict protein domains.

\section{Cell Lines}

All mammalian cells were grown in high-glucose Dulbecco's modified Eagle's medium (DMEM) supplemented with $10 \%$ FBS, $100 \mu \mathrm{g} / \mathrm{ml}$ geneticin (mt-AEQ HeLa), $2 \mu \mathrm{g} / \mathrm{mL}$ puromycin (shMCU HeLa), $10 \mu \mathrm{g} / \mathrm{mL}$ blasticidin (Hs-MCU, Nc-MCU, Af-MCU, HsMTSAf-MCU, HsMTSNc-MCU, HsMICU1, and Hs-MICU1meF overexpressing HeLa or HEK-293 cells) at $37^{\circ} \mathrm{C}$ and $5 \% \mathrm{CO}_{2}$. The lentiviral vector pLX304 was obtained from the Broad Institute's RNAi Consortium and used for expressing V5-tagged cDNAs. All chemicals were purchased from Sigma-Aldrich, unless specified. 
Cell lysates and crude mitochondria were prepared from cultured HeLa cells as previously described (Wettmarshausen and Perocchi, 2017) and analyzed by alkaline carbonate extraction.

\section{Measurements of Mitochondrial Calcium Uptake in HeLa Cells}

Mitochondrial $\mathrm{Ca}^{2+}$ uptake was measured by mt-AEQ-based measurements of $\mathrm{Ca}^{2+}$-dependent light kinetics upon $100 \mu \mathrm{M}$ histamine stimulation as previously described (Arduino et al., 2017).

\section{Yeast Strains}

Yeast strains expressing mt-AEQ or cyt-AEQ were generated by transforming the yeast wildtype YPH499 strain and selecting transformants in glucose medium lacking uracil (Sikorski and Hieter, 1989). Yeast strains expressing different combinations of Hs-EMRE, Hs-MCU, HsMICU1 and their mutants were generated by simultaneously transforming the YPH499 strain with the respective plasmids and by selecting transformants on glucose medium lacking uracil (AEQ), histidine (Hs-MCU), leucine (Hs-EMRE), and tryptophan (Hs-MICU1) as selection markers.

\section{Measurements of Calcium Kinetics in Yeast}

In vivo analyses of cytosolic and mitochondrial $\mathrm{Ca}^{2+}$ kinetics in yeast cells were performed by mt-AEQ and cyt-AEQ-based measurements of $\mathrm{Ca}^{2+}$-dependent aequorin light response upon $\mathrm{CaCl}_{2}(1 \mathrm{mM})$ and glucose addition $(100 \mathrm{mM}) . \mathrm{Ca}^{2+}$ uptake by mitochondria isolated from yeast strains expressing Hs-MICU1 was measured with Calcium Green-5N upon $\mathrm{CaCl}_{2}$ injection (100 $\mu \mathrm{M}$ final concentration).

\section{Yeast Growth Measurement}

Yeast cultures were grown for 48-72 hours in a selective lactate medium (S-LAC) under different environmental stresses and their doubling time was calculated.

\section{MTT Assay}

A colorimetric 3-(4,5- dimethylthiazol- 2- yl)- 2,5- diphenyltetrazolium bromide (MTT) metabolic activity assay was used to determine cell viability.

\section{Quantification and Statistical Analysis}

Data are represented as mean \pm SEM and the statistical analysis of each experiment is described in the figure legends. Normal distribution was tested by Shapiro-Wilk normality test. Differences between two datasets were evaluated by two-tailed unpaired Student's $t$ test. Statistical tests between multiple datasets and conditions were carried out using one-way analysis of variance (ANOVA) followed by Tukey's or Dunnett's Multiple Comparison. Statistical analyses were performed using GraphPad Prism.

\section{SUPPLEMENTAL INFORMATION}

Supplemental Information includes Supplemental Experimental Procedures. 


\section{ACKNOWLEDGEMENTS}

We thank Dr. Daniela M. Arduino for critical reading of the manuscript. We acknowledge support from the German Research Foundation (DFG) under the Emmy Noether Programme (PE 2053/1-1 to F.P. and J.W.); the Munich Center for Systems Neurology (SyNergy EXC 1010 to F.P.); the Juniorverbund in der Systemmedizin 'mitOmics' (FKZ 01ZX1405B to V.G. and A.L.); The Bert L \& N Kuggie Vallee Foundation (to F.P.); the DFG (MO1944/1-2 to D.M.); The Spanish Ministry of Economy, Industry, and Competitiveness (MEIC; BFU2015-67107) and from the European Union's Horizon 2020 research and innovation programme under the grant agreement ERC-2016-724173 (to T.G. and A.P.).

\section{AUTHOR CONTRIBUTIONS}

Conceptualization, F.P.; Methodology, V.G., J.W., D.M., T.G.; Formal Analysis, V.G., J.W., A.A.P., A.L., Y.C.; Resources, F.P., D.M.; Writing-Original Draft, F.P., V.G., J.W.; Visualization, F.P., V.G., J.W.; Supervision, F.P.; Funding Acquisition, F.P., D.M., and T.G.

\section{DECLARATION OF INTERESTS}

The authors declare no competing interests.

\section{REFERENCES}

Antony, A.N., Paillard, M., Moffat, C., Juskeviciute, E., Correnti, J., Bolon, B., Rubin, E., Csordás, G., Seifert, E.L., Hoek, J.B., et al. (2016). MICU1 regulation of mitochondrial $\mathrm{Ca}(2+)$ uptake dictates survival and tissue regeneration. Nature communications 7, 10955.

Arduino, D.M., Wettmarshausen, J., Vais, H., Navas-Navarro, P., Cheng, Y., Leimpek, A., Ma, Z., Delrio-Lorenzo, A., Giordano, A., Garcia-Perez, C., et al. (2017). Systematic Identification of MCU Modulators by Orthogonal Interspecies Chemical Screening. Molecular cell 67, 711723.e717.

Baughman, J.M., Perocchi, F., Girgis, H.S., Plovanich, M., Belcher-Timme, C.A., Sancak, Y., Bao, X.R., Strittmatter, L., Goldberger, O., Bogorad, R.L., et al. (2011). Integrative genomics identifies MCU as an essential component of the mitochondrial calcium uniporter. Nature 476, 341-345.

Berridge, M.J., Lipp, P., and Bootman, M.D. (2000). The versatility and universality of calcium signalling. Nature reviews Molecular cell biology 1,11-21.

Bick, A.G., Calvo, S.E., and Mootha, V.K. (2012). Evolutionary diversity of the mitochondrial calcium uniporter. Science (New York, NY) 336, 886.

Bultynck, G., Heath, V.L., Majeed, A.P., Galan, J.M., Haguenauer-Tsapis, R., and Cyert, M.S. (2006). SIm1 and slm2 are novel substrates of the calcineurin phosphatase required for heat stress-induced endocytosis of the yeast uracil permease. Molecular and cellular biology 26, 4729-4745.

Cao, C., Wang, S., Cui, T., Su, X.-C., and Chou, J.J. (2017). Ion and inhibitor binding of the double-ring ion selectivity filter of the mitochondrial calcium uniporter. Proceedings of the National Academy of Sciences of the United States of America 114, E2846-E2851.

Carafoli, E., and Lehninger, A.L. (1971). A survey of the interaction of calcium ions with mitochondria from different tissues and species. The Biochemical journal 122, 681-690. 
Chaudhuri, D., Sancak, Y., Mootha, V.K., and Clapham, D.E. (2013). MCU encodes the pore conducting mitochondrial calcium currents. eLife 2, e00704.

Cheng, Y., and Perocchi, F. (2015). ProtPhylo: identification of protein-phenotype and proteinprotein functional associations via phylogenetic profiling. Nucleic acids research 43, W160-168.

Csordas, G., Golenar, T., Seifert, E.L., Kamer, K.J., Sancak, Y., Perocchi, F., Moffat, C., Weaver, D., de la Fuente Perez, S., Bogorad, R., et al. (2013). MICU1 controls both the threshold and cooperative activation of the mitochondrial $\mathrm{Ca}(2)(+)$ uniporter. Cell metabolism 17, 976-987.

Cyert, M.S. (2003). Calcineurin signaling in Saccharomyces cerevisiae: how yeast go crazy in response to stress. Biochemical and biophysical research communications 311, 1143-1150.

de Juan, D., Pazos, F., and Valencia, A. (2013). Emerging methods in protein co-evolution. Nature reviews Genetics 14, 249-261.

De Stefani, D., Raffaello, A., Teardo, E., Szabo, I., and Rizzuto, R. (2011). A forty-kilodalton protein of the inner membrane is the mitochondrial calcium uniporter. Nature $476,336-340$.

De Stefani, D., Rizzuto, R., and Pozzan, T. (2016). Enjoy the Trip: Calcium in Mitochondria Back and Forth. Annual review of biochemistry 85, 161-192.

Deluca, H.F., and Engstrom, G.W. (1961). Calcium uptake by rat kidney mitochondria. Proceedings of the National Academy of Sciences of the United States of America 47, 17441750.

Denton, R.M. (2009). Regulation of mitochondrial dehydrogenases by calcium ions. Biochim Biophys Acta 1787, 1309-1316.

Edlind, T., Smith, L., Henry, K., Katiyar, S., and Nickels, J. (2002). Antifungal activity in Saccharomyces cerevisiae is modulated by calcium signalling. Molecular microbiology $46,257-$ 268.

Ernster, L., Nakarawa, T. and Nordenbrand, K. (1978). in: The Proton and Calcium Pumps (Azzone, G. F. et al. eds) pp. 163-176, Elsevier/North Holland, Amsterdam, New York.

Farcasanu, I.C., Hirata, D., Tsuchiya, E., Nishiyama, F., and Miyakawa, T. (1995). Protein phosphatase $2 \mathrm{~B}$ of Saccharomyces cerevisiae is required for tolerance to manganese, in blocking the entry of ions into the cells. European journal of biochemistry 232, 712-717.

Fieni, F., Lee, S.B., Jan, Y.N., and Kirichok, Y. (2012). Activity of the mitochondrial calcium uniporter varies greatly between tissues. Nature communications 3, 1317.

Finn, R.D., Coggill, P., Eberhardt, R.Y., Eddy, S.R., Mistry, J., Mitchell, A.L., Potter, S.C., Punta, M., Qureshi, M., Sangrador-Vegas, A., et al. (2016). The Pfam protein families database: towards a more sustainable future. Nucleic Acids Research 44, D279-D285.

Gavin, C.E., Gunter, K.K., and Gunter, T.E. (1990). Manganese and calcium efflux kinetics in brain mitochondria. Relevance to manganese toxicity. Biochemical Journal 266, 329-334.

Gonçalves, A.P., Cordeiro, J.M., Monteiro, J., Lucchi, C., Correia-de-Sá, P., and Videira, A. (2015). Involvement of mitochondrial proteins in calcium signaling and cell death induced by staurosporine in Neurospora crassa. Biochimica et Biophysica Acta (BBA) - Bioenergetics 1847, 1064-1074.

Groppi, S., Belotti, F., Brandao, R.L., Martegani, E., and Tisi, R. (2011). Glucose-induced calcium influx in budding yeast involves a novel calcium transport system and can activate calcineurin. Cell calcium 49, 376-386. 
Gunshin, H., Mackenzie, B., Berger, U.V., Gunshin, Y., Romero, M.F., Boron, W.F., Nussberger, S., Gollan, J.L., and Hediger, M.A. (1997). Cloning and characterization of a mammalian protoncoupled metal-ion transporter. Nature 388, 482-488.

Gupta, S.S., Ton, V.K., Beaudry, V., Rulli, S., Cunningham, K., and Rao, R. (2003). Antifungal activity of amiodarone is mediated by disruption of calcium homeostasis. The Journal of biological chemistry $278,28831-28839$.

Heuck, S., Gerstmann, U.C., Michalke, B., and Kanter, U. (2010). Genome-wide analysis of caesium and strontium accumulation in Saccharomyces cerevisiae. Yeast (Chichester, England) $27,817-835$

Hillered, L., Muchiri, P.M., Nordenbrand, K., and Ernster, L. (1983). Mn2+ prevents the Ca2+induced inhibition of ATP synthesis in brain mitochondria. FEBS letters 154, 247-250.

Holzerova, E., Danhauser, K., Haack, T.B., Kremer, L.S., Melcher, M., Ingold, I., Kobayashi, S., Terrile, C., Wolf, P., Schaper, J., et al. (2016). Human thioredoxin 2 deficiency impairs mitochondrial redox homeostasis and causes early-onset neurodegeneration. Brain : a journal of neurology $139,346-354$.

Hughes, B.P., and Exton, J.H. (1983). Effect of micromolar concentrations of manganese ions on calcium-ion cycling in rat liver mitochondria. The Biochemical journal 212, 773-782.

Kamer, K.J., Grabarek, Z., and Mootha, V.K. (2017). High-affinity cooperative $\mathrm{Ca}(2+)$ binding by MICU1-MICU2 serves as an on-off switch for the uniporter. EMBO reports 18, 1397-1411.

Kirichok, Y., Krapivinsky, G., and Clapham, D.E. (2004). The mitochondrial calcium uniporter is a highly selective ion channel. Nature $427,360-364$.

Kovacs-Bogdan, E., Sancak, Y., Kamer, K.J., Plovanich, M., Jambhekar, A., Huber, R.J., Myre, M.A., Blower, M.D., and Mootha, V.K. (2014). Reconstitution of the mitochondrial calcium uniporter in yeast. Proceedings of the National Academy of Sciences of the United States of America 111, 8985-8990.

Lewis-Smith, D., Kamer, K.J., Griffin, H., Childs, A.M., Pysden, K., Titov, D., Duff, J., Pyle, A., Taylor, R.W., Yu-Wai-Man, P., et al. (2016). Homozygous deletion in MICU1 presenting with fatigue and lethargy in childhood. Neurology Genetics 2, e59.

Liu, J.C., Liu, J., Holmstrom, K.M., Menazza, S., Parks, R.J., Fergusson, M.M., Yu, Z.X., Springer, D.A., Halsey, C., Liu, C., et al. (2016). MICU1 Serves as a Molecular Gatekeeper to Prevent In Vivo Mitochondrial Calcium Overload. Cell Rep 16, 1561-1573.

Logan, C.V., Szabadkai, G., Sharpe, J.A., Parry, D.A., Torelli, S., Childs, A.M., Kriek, M., Phadke, R., Johnson, C.A., Roberts, N.Y., et al. (2014). Loss-of-function mutations in MICU1 cause a brain and muscle disorder linked to primary alterations in mitochondrial calcium signaling. Nature genetics 46, 188-193.

Mallilankaraman, K., Doonan, P., Cardenas, C., Chandramoorthy, H.C., Muller, M., Miller, R., Hoffman, N.E., Gandhirajan, R.K., Molgo, J., Birnbaum, M.J., et al. (2012). MICU1 is an essential gatekeeper for MCU-mediated mitochondrial $\mathrm{Ca}(2+)$ uptake that regulates cell survival. Cell $151,630-644$.

Mammucari, C., Raffaello, A., Vecellio Reane, D., Gherardi, G., De Mario, A., and Rizzuto, R. (2018). Mitochondrial calcium uptake in organ physiology: from molecular mechanism to animal models. Pflugers Archiv : European journal of physiology.

Matlib, M.A., Zhou, Z., Knight, S., Ahmed, S., Choi, K.M., Krause-Bauer, J., Phillips, R., Altschuld, R., Katsube, Y., Sperelakis, N., et al. (1998). Oxygen-bridged dinuclear ruthenium amine complex specifically inhibits $\mathrm{Ca} 2+$ uptake into mitochondria in vitro and in situ in single cardiac myocytes. The Journal of biological chemistry $273,10223-10231$. 
McCormack, J.G., Halestrap, A.P., and Denton, R.M. (1990). Role of calcium ions in regulation of mammalian intramitochondrial metabolism. Physiological reviews 70, 391-425.

Medvedeva, Y.V., and Weiss, J.H. (2014). Intramitochondrial Zn2+ accumulation via the Ca2+ uniporter contributes to acute ischemic neurodegeneration. Neurobiology of disease 68, 137144.

Mela, L., and Chance, B. (1968). Spectrophotometric measurements of the kinetics of Ca2+ and Mn2+ accumulation in mitochondria. Biochemistry 7, 4059-4063.

Murgia, M., and Rizzuto, R. (2015). Molecular diversity and pleiotropic role of the mitochondrial calcium uniporter. Cell calcium 58, 11-17.

Musa, S., Eyaid, W., Kamer, K., Ali, R., Al-Mureikhi, M., Shahbeck, N., Al Mesaifri, F., Makhseed, N., Mohamed, Z., AlShehhi, W.A., et al. (2018). A Middle Eastern Founder Mutation Expands the Genotypic and Phenotypic Spectrum of Mitochondrial MICU1 Deficiency: A Report of 13 Patients. JIMD reports.

Nakajima-Shimada, J., lida, H., Tsuji, F.I., and Anraku, Y. (1991). Monitoring of intracellular calcium in Saccharomyces cerevisiae with an apoaequorin cDNA expression system. Proceedings of the National Academy of Sciences of the United States of America 88, 68786882.

Nakamura, T., Liu, Y., Hirata, D., Namba, H., Harada, S., Hirokawa, T., and Miyakawa, T. (1993). Protein phosphatase type 2B (calcineurin)-mediated, FK506-sensitive regulation of intracellular ions in yeast is an important determinant for adaptation to high salt stress conditions. The EMBO journal 12, 4063-4071.

O'Neal, S.L., and Zheng, W. (2015). Manganese Toxicity Upon Overexposure: a Decade in Review. Current environmental health reports 2, 315-328.

Oxenoid, K., Dong, Y., Cao, C., Cui, T., Sancak, Y., Markhard, A.L., Grabarek, Z., Kong, L., Liu, Z., Ouyang, B., et al. (2016). Architecture of the mitochondrial calcium uniporter. Nature 533, 269-273.

Pagani, A., Villarreal, L., Capdevila, M., and Atrian, S. (2007). The Saccharomyces cerevisiae Crs5 Metallothionein metal-binding abilities and its role in the response to zinc overload. Molecular microbiology 63, 256-269.

Paillard, M., Csordás, G., Szanda, G., Golenár, T., Debattisti, V., Bartok, A., Wang, N., Moffat, C., Seifert, E.L., Spät, A., et al. (2017). Tissue-Specific Mitochondrial Decoding of Cytoplasmic $\mathrm{Ca} 2+$ Signals Is Controlled by the Stoichiometry of MICU1/2 and MCU. Cell Reports 18, 22912300.

Patron, M., Checchetto, V., Raffaello, A., Teardo, E., Vecellio Reane, D., Mantoan, M., Granatiero, V., Szabò, I., De Stefani, D., and Rizzuto, R. (2014). MICU1 and MICU2 Finely Tune the Mitochondrial $\mathrm{Ca}<\sup >2+</$ sup $>$ Uniporter by Exerting Opposite Effects on MCU Activity. Molecular cell 53, 726-737.

Patron, M., Granatiero, V., Espino, J., Rizzuto, R., and De Stefani, D. (2018). MICU3 is a tissuespecific enhancer of mitochondrial calcium uptake. Cell death and differentiation.

Peiter, E., Fischer, M., Sidaway, K., Roberts, S.K., and Sanders, D. (2005). The Saccharomyces cerevisiae Ca2+ channel Cch1pMid1p is essential for tolerance to cold stress and iron toxicity. FEBS letters 579, 5697-5703.

Perocchi, F., Gohil, V.M., Girgis, H.S., Bao, X.R., McCombs, J.E., Palmer, A.E., and Mootha, V.K. (2010). MICU1 encodes a mitochondrial EF hand protein required for $\mathrm{Ca}(2+)$ uptake. Nature 467, 291-296.

Philpott, C.C. (2012). Coming into view: eukaryotic iron chaperones and intracellular iron delivery. The Journal of biological chemistry 287, 13518-13523. 
Plovanich, M., Bogorad, R.L., Sancak, Y., Kamer, K.J., Strittmatter, L., Li, A.A., Girgis, H.S., Kuchimanchi, S., De Groot, J., Speciner, L., et al. (2013). MICU2, a paralog of MICU1, resides within the mitochondrial uniporter complex to regulate calcium handling. PLoS One 8, e55785.

Prole, D.L., and Taylor, C.W. (2012). Identification and Analysis of Cation Channel Homologues in Human Pathogenic Fungi. PLoS ONE 7, e42404.

Raffaello, A., De Stefani, D., Sabbadin, D., Teardo, E., Merli, G., Picard, A., Checchetto, V., Moro, S., Szabo, I., and Rizzuto, R. (2013). The mitochondrial calcium uniporter is a multimer that can include a dominant-negative pore-forming subunit. The EMBO journal 32, 2362-2376.

Romslo, I., and Flatmark, T. (1973). Energy-dependent accumulation of iron by isolated rat liver mitochondria. II. Relationship to the active transport of Ca2+. Biochim Biophys Acta 325, 38-46.

Sancak, Y., Markhard, A.L., Kitami, T., Kovacs-Bogdan, E., Kamer, K.J., Udeshi, N.D., Carr, S.A., Chaudhuri, D., Clapham, D.E., Li, A.A., et al. (2013). EMRE is an essential component of the mitochondrial calcium uniporter complex. Science (New York, NY) 342, 1379-1382.

Saris, N.-E. (2012). Mitochondrial Uptake of Ca2+ and Other Bivalent Cations. Biochem Anal Biochem 1:112.

Saris, N.-E.L., and Kaija, N. (1994). Is Zn2+ transported by the mitochondrial calcium uniporter? FEBS letters 356, 195-198.

Senguen, F.T., and Grabarek, Z. (2012). X-ray structures of magnesium and manganese complexes with the $\mathrm{N}$-terminal domain of calmodulin: insights into the mechanism and specificity of metal ion binding to an EF-hand. Biochemistry 51, 6182-6194.

Serrano, R., Bernal, D., Simon, E., and Arino, J. (2004). Copper and iron are the limiting factors for growth of the yeast Saccharomyces cerevisiae in an alkaline environment. The Journal of biological chemistry $279,19698-19704$.

Shirran, S.L., and Barran, P.E. (2009). The Use of ESI-MS to Probe the Binding of Divalent Cations to Calmodulin. Journal of the American Society for Mass Spectrometry 20, 1159-1171.

Sikorski, R.S., and Hieter, P. (1989). A system of shuttle vectors and yeast host strains designed for efficient manipulation of DNA in Saccharomyces cerevisiae. Genetics 122, 19-27.

Smith, M.R., Fernandes, J., Go, Y.M., and Jones, D.P. (2017). Redox dynamics of manganese as a mitochondrial life-death switch. Biochemical and biophysical research communications 482, 388-398.

Song, J., Liu, X., Zhai, P., Huang, J., and Lu, L. (2016). A putative mitochondrial calcium uniporter in $\mathrm{A}$. fumigatus contributes to mitochondrial $\mathrm{Ca}(2+)$ homeostasis and stress responses. Fungal genetics and biology : FG \& B 94, 15-22.

Sripetchwandee, J., KenKnight, S.B., Sanit, J., Chattipakorn, S., and Chattipakorn, N. (2014). Blockade of mitochondrial calcium uniporter prevents cardiac mitochondrial dysfunction caused by iron overload. Acta physiologica (Oxford, England) 210, 330-341.

Tai, Y.K., Chew, K.C., Tan, B.W., Lim, K.L., and Soong, T.W. (2016). Iron mitigates DMT1mediated manganese cytotoxicity via the ASK1-JNK signaling axis: Implications of iron supplementation for manganese toxicity. Scientific reports 6, 21113.

Vainio, H., Mela, L., and Chance, B. (1970). Energy dependent bivalent cation translocation in rat liver mitochondria. European journal of biochemistry 12, 387-391.

Vasington, F.D., Gazzotti, P., Tiozzo, R., and Carafoli, E. (1972). The effect of ruthenium red on $\mathrm{Ca} 2+$ transport and respiration in rat liver mitochondria. Biochim Biophys Acta 256, 43-54. 
Vasington, F.D., and Murphy, J.V. (1962). Ca ion uptake by rat kidney mitochondria and its dependence on respiration and phosphorylation. The Journal of biological chemistry 237, 26702677.

Vecellio Reane, D., Vallese, F., Checchetto, V., Acquasaliente, L., Butera, G., De Filippis, V., Szabo, I., Zanotti, G., Rizzuto, R., and Raffaello, A. (2016). A MICU1 Splice Variant Confers High Sensitivity to the Mitochondrial $\mathrm{Ca}(2+)$ Uptake Machinery of Skeletal Muscle. Molecular cell 64, 760-773.

Vinogradov, A., and Scarpa, A. (1973). The initial velocities of calcium uptake by rat liver mitochondria. The Journal of biological chemistry 248, 5527-5531.

Wettmarshausen, J., and Perocchi, F. (2017). Isolation of Functional Mitochondria from Cultured Cells and Mouse Tissues. Methods in molecular biology (Clifton, NJ) 1567, 15-32.

Yamamoto, T., Yamagoshi, R., Harada, K., Kawano, M., Minami, N., Ido, Y., Kuwahara, K., Fujita, A., Ozono, M., Watanabe, A., et al. (2016). Analysis of the structure and function of EMRE in a yeast expression system. Biochim Biophys Acta 1857, 831-839.

\section{MAIN FIGURE TITLES AND LEGENDS}

Figure 1. Phylogenetic profiling of MCU and MICU1.

(A) Phylogenetic distribution of MCU and MICU1 homologs (blue, percentage of amino acids match length) across 247 eukaryotes. MTS, mitochondrial targeting sequence from MitoProt.

(B) Schematic of ectopically expressed fungal MCU constructs and protein domains (CCD, coiled-coil domain; TM, transmembrane domain). DXXE motif and MTS cleavage site prediction (arrow) are also shown.

(C) Analysis of whole cell (W) and mitochondrial (M) fractions isolated from MCU knocked-down (shMCU) HeLa cells stably expressing human (Hs-MCU), N. crassa (Nc-MCU), or A. fumigatus (Af-MCU) MCU fused with a C-terminal V5-tag and compared to wild-type (WT). HsMTSAf-MCU and HsMTSNc-MCU refer to A. fumigatus and $N$. crassa MCU constructs fused at the $\mathrm{N}$-terminal to the MTS of Hs-MCU (HsMTS). NI, not infected.

(D) Analysis of mitochondrial soluble (S) and membrane pellet (P) fractions isolated from shMCU HeLa cells expressing Af-MCU and Nc-MCU with and without HsMTS.

$(\mathbf{E}, \mathbf{F})$ Representative traces and quantification of mitochondrial $\mathrm{Ca}^{2+}$ kinetics in shMCU HeLa cells expressing $A$. fumigatus $(E)$ or $N$. crassa $(F)$ MCU constructs upon histamine (His) stimulation (100 $\mu \mathrm{M}$ final concentration). All data represent mean $\pm \mathrm{SEM} ; n=6-8 ;{ }^{* * *} p<0.0001$, one-way ANOVA with Tukey's Multiple Comparison Test.

Figure 2. In vivo reconstitution of mitochondrial calcium uptake in yeast.

(A) Schematic of the $\mathrm{Ca}^{2+}$ homeostasis system and glucose-induced calcium (GIC) signaling in S. cerevisiae. Hs-MCU, human MCU; Hs-EMRE, human EMRE; HXT, hexose transporter; $\mathrm{HACS}$, high-affinity $\mathrm{Ca}^{2+}$ transport system; $\mathrm{VCX} 1$, vacuolar $\mathrm{H}^{+} / \mathrm{Ca}^{2+}$ exchanger; $\mathrm{PMC1}$, vacuolar $\mathrm{Ca}^{2+-A T P a s e}$ PMR1, ER/golgi $\mathrm{Ca}^{2+-A T P a s e ; ~ m t A E Q, ~ m i t o c h o n d r i a-t a r g e t e d ~ a e q u o r i n ; ~ Y V C 1, ~}$ TRPC-type $\mathrm{Ca}^{2+}$ channel; CaN, calcineurin; CaM, calmodulin; Crz1, calcineurin-dependent transcription factor; $\mathrm{Crz}^{\mathrm{P}}$, phosphorylated $\mathrm{Crz1}$. 
(B) Dynamics and quantification of cytosolic $\mathrm{Ca}^{2+}$ kinetics in yeast cells expressing a cytosolic aequorin (cyt-AEQ) upon GIC stimulation in presence of different extracellular $\mathrm{CaCl}_{2}$ concentrations $(n=3) ;{ }^{*} p<0.05,{ }^{* *} p<0.01,{ }^{* * *} p<0.001$, one-way ANOVA with Dunnett's Multiple Comparison Test.

(C) Dynamics and quantification of mitochondrial $\mathrm{Ca}^{2+}$ kinetics in yeast cells expressing $\mathrm{mtAEQ}$, Hs-EMRE, and either wild type or mutated Hs-MCU upon GIC stimulation in presence of $1 \mathrm{mM}$ $\mathrm{CaCl}_{2}(\mathrm{n}=3) ;{ }^{* *} \mathrm{p}<0.0001$, one-way ANOVA with Tukey's multiple comparisons test. Inset, immunoblot analysis of cytosolic (C) and mitochondrial (M) fractions.

(D) Dynamics and quantification of mitochondrial $\mathrm{Ca}^{2+}$ kinetics in yeast cells expressing $\mathrm{mtAEQ}$, $\mathrm{Hs}-\mathrm{EMRE}$ and $\mathrm{Hs}-\mathrm{MCU}$ upon GIC stimulation in presence of different extracellular $\mathrm{CaCl}_{2}$ concentrations $(n=3) ;{ }^{*} p<0.05,{ }^{* *} p<0.01$, one-way ANOVA with Dunnett's multiple comparisons test.

(E) Dynamics and quantification of cytosolic $\mathrm{Ca}^{2+}$ kinetics in yeast cells expressing cyt-AEQ with either empty vectors (p425, p423) or Hs-EMRE and wild type or mutant Hs-MCU upon GIC stimulation in presence of different extracellular $\mathrm{CaCl}_{2}$ concentrations $(n=3)$; ${ }^{*} p<0.05$, ${ }^{* *} p<$ $0.01,{ }^{* * *} p<0.001$, one-way ANOVA with Dunnett's multiple comparisons test.

(F) Immunoblot analysis of cytosolic (C) and mitochondrial (M) fractions isolated from yeast strains expressing mtAEQ, Hs-MCU, Hs-EMRE and either an empty vector (p414), human wildtype MICU1 (Hs-MICU1), or EF-hands mutant MICU1 (Hs-MICU1mEF).

(G) Dynamics and quantification of mitochondrial $\mathrm{Ca}^{2+}$ kinetics in the yeast strains described in

(F) upon GIC stimulation in presence of $1 \mathrm{mM} \mathrm{CaCl}_{2}(\mathrm{n}=3)$; ${ }^{*} \mathrm{p}<0.05$, ${ }^{* *} \mathrm{p}<0.001$, one-way ANOVA with Dunnett's multiple comparisons test.

(H) Representative traces and quantification of extracellular $\mathrm{Ca}^{2+}$ clearance by mitochondria isolated from the yeast strains described in (F) upon addition of $100 \mu \mathrm{M}$ final concentration of $\mathrm{CaCl}_{2}(\mathrm{n}=3) ;{ }^{* * *} \mathrm{p}<0.0001$, one-way ANOVA with Tukey's Multiple Comparison Test. $10 \mu \mathrm{M}$ Ru360 (specific MCU inhibitor) was added as a positive control.

All data represent mean \pm SEM.

\section{Figure 3. MCU impairs yeast tolerance to iron and manganese stress.}

(A-E) Quantification of growth rate and average growth curve of yeast strains expressing empty vectors (p423 and p425) or Hs-EMRE with wild-type or mutated $\mathrm{Hs}-\mathrm{MCU}$ at $30^{\circ} \mathrm{C}$ and $37^{\circ} \mathrm{C}(\mathrm{A})$, and at increasing concentrations of miconazole (B), amiodarone (C), $\mathrm{NaCl}(\mathrm{D})$, or heavy metals (E). $\mathrm{SrCl}_{2}$, strontium chloride; $\mathrm{CuCl}_{2}$, copper chloride; $\mathrm{ZnCl}_{2}$, zinc chloride; $\mathrm{FeCl}_{2}$, iron chloride; $\mathrm{MnCl}_{2}$, manganese chloride. Data represent mean $\pm \mathrm{SEM} ; \mathrm{n}=4 ;{ }^{* * *} \mathrm{p}<0.0001$, one-way ANOVA with Tukey's Multiple Comparison Test.

\section{Figure 4. MICU1 protects yeast and human cells from manganese-induced cell death.}

(A, B) Quantification of growth rate and average growth curve of yeast strains expressing HsMCU, Hs-EMRE and either empty vector (p414), Hs-MICU1 or Hs-MICU1mEF and treated with $\mathrm{FeCl}_{2}(\mathrm{~A})$ or $\mathrm{MnCl}_{2}(\mathrm{~B}) ; \mathrm{n}=4 ;{ }^{* * *} \mathrm{p}<0.0001$, one-way ANOVA with Tukey's Multiple Comparison Test. 
(C, D) Cell viability assays of wild-type (WT) and MICU1 knockout (MICU1-KO) HEK-293 cells treated for 48 hours with $\mathrm{FeCl}_{2}(\mathrm{C})$ or $\mathrm{MnCl}_{2}(\mathrm{D}) ; \mathrm{n}=4$.

(E) Cell viability assays of uninfected WT (NI) and MICU1-KO cells that were either MOCKtreated or rescued by lentiviral expression of Hs-MICU1 or Hs-MICU1 $1_{\mathrm{mEF}}$ upon $\mathrm{MnCl}_{2}$ treatment for 48 hours; $n=4 ;{ }^{* * *} p<0.001$, one-way ANOVA with Tukey's Multiple Comparison Test. Right, immunoblot analysis of whole cell lysates from all cell lines.

$(\mathbf{F}, \mathbf{G})$ Cell viability assays of WT and MICU1-KO HEK-293 cells treated for 48 hours with $\mathrm{MnCl}_{2}$ in the presence or absence of idebenone $(n=4)$ or $\mathrm{FeCl}_{2}(n=3)$.

(H) Cell viability assays of WT and MICU1-KO HEK-293 cells pre-treated with either $\mathrm{FeCl}_{2}$ or vehicle (water) for 24 hours followed by 48 hours of incubation with $\mathrm{MnCl}_{2}(\mathrm{n}=3)$.

All data represent mean \pm SEM and are reported as the percentage of viable cells in untreated samples. 
Figure 1

A
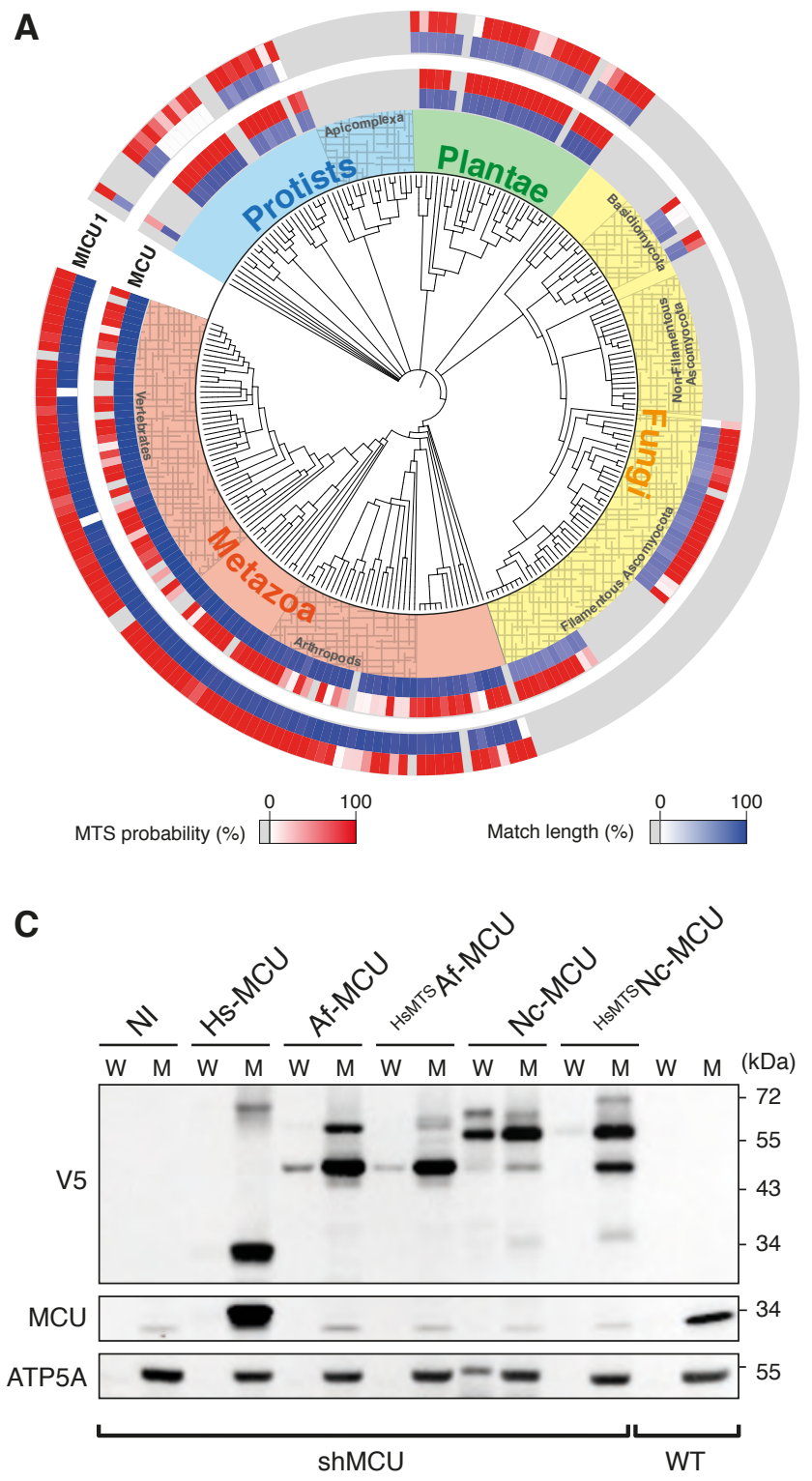

E
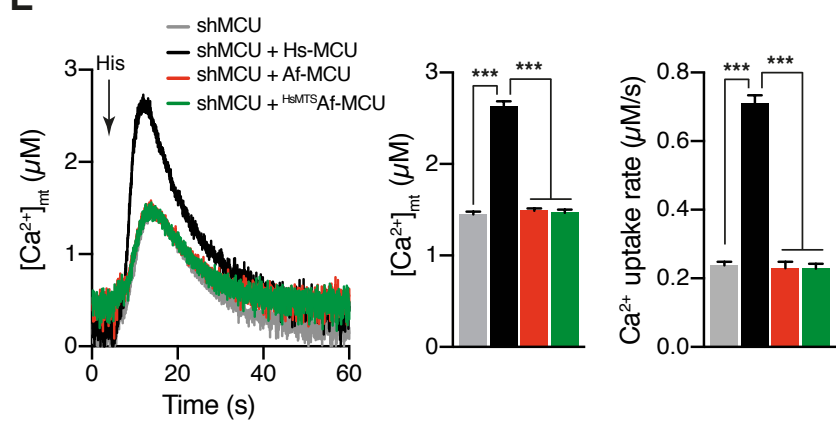

B

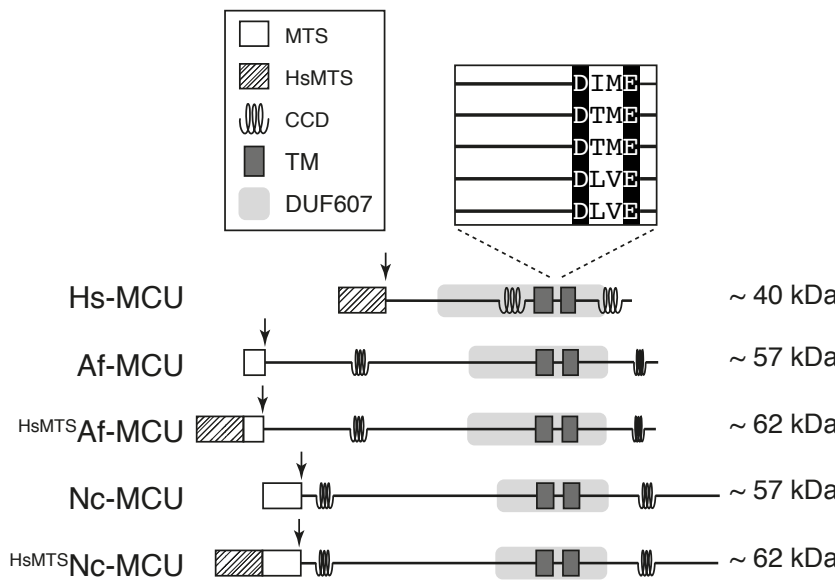

D

Af-MCU

Nc-MCU
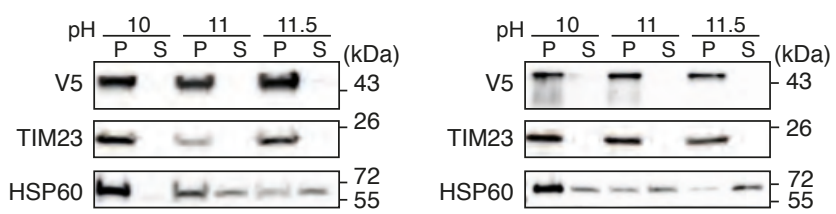

HsMTSAf-MCU
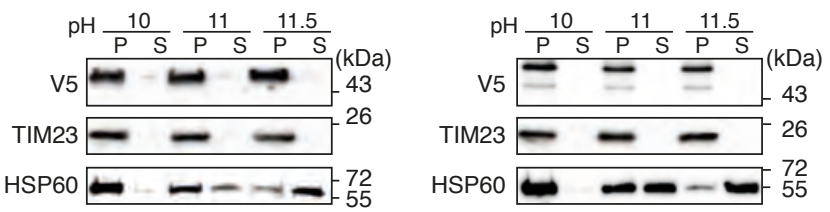

F
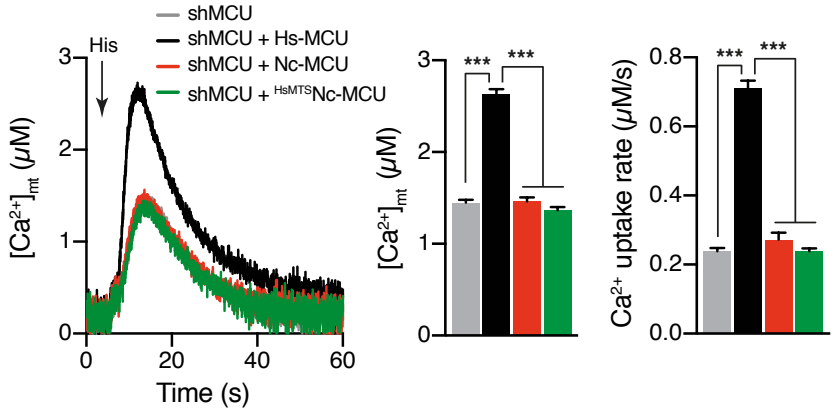
B
Unstimulated

GIC response

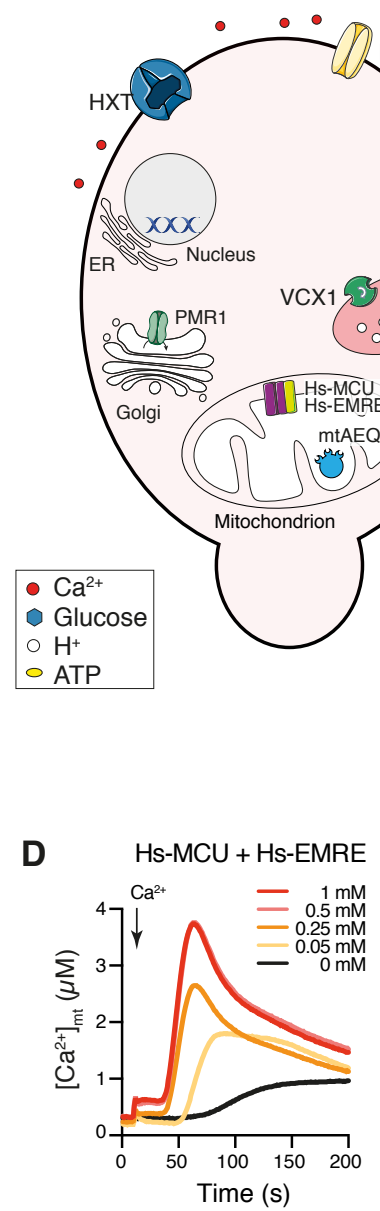

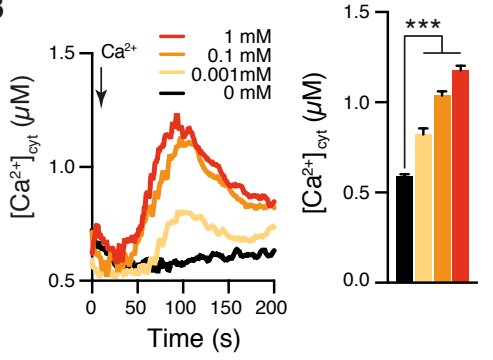

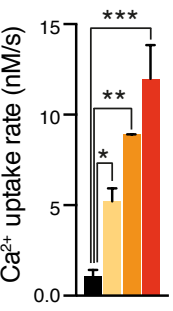

C
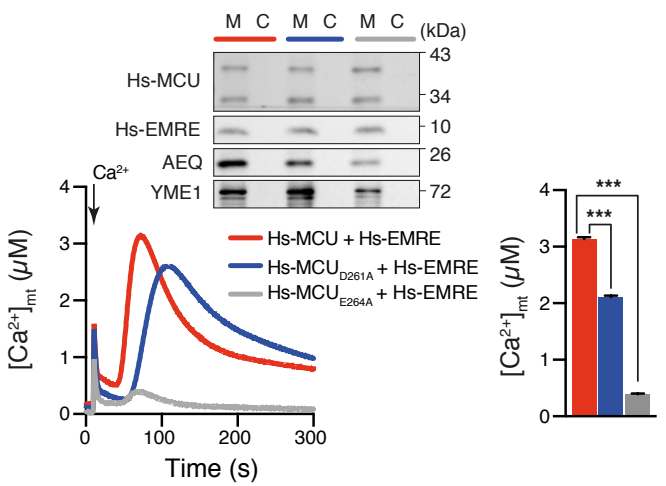

E
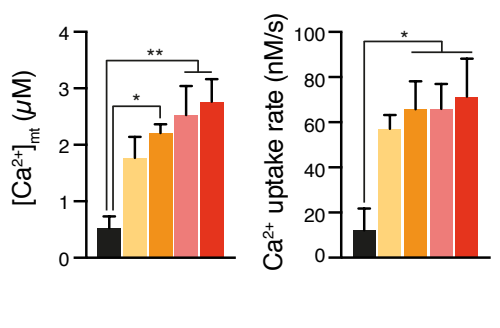

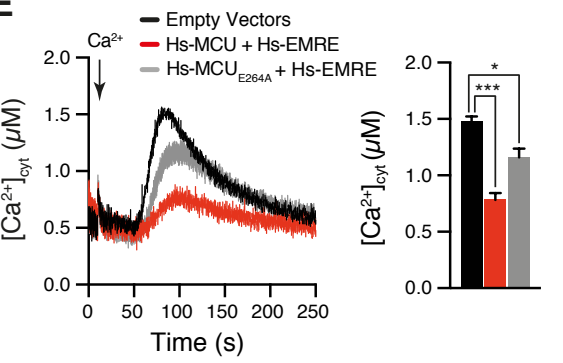

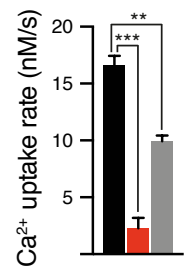

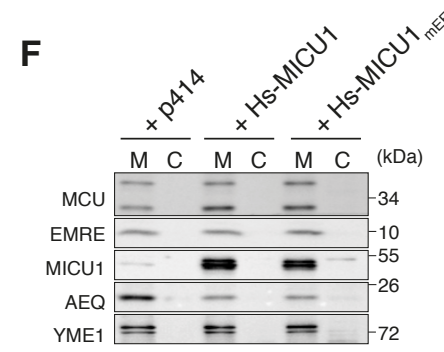

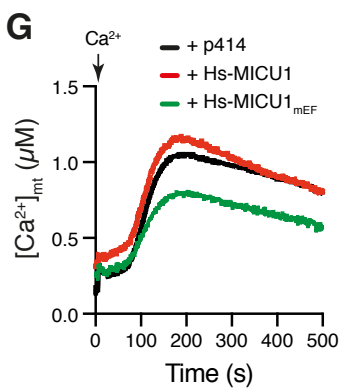
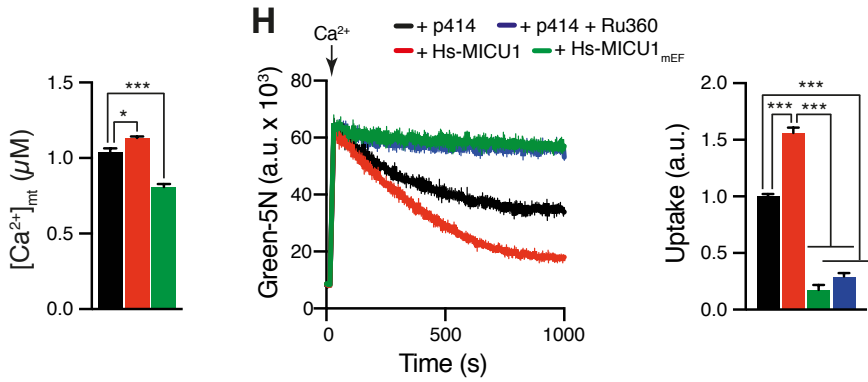
EAgure 3

Temperature
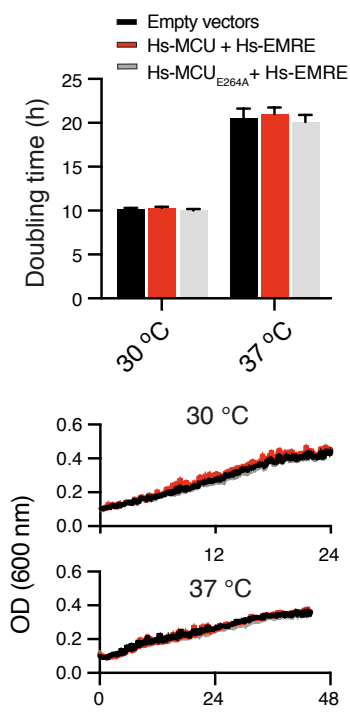

Time (h)
B
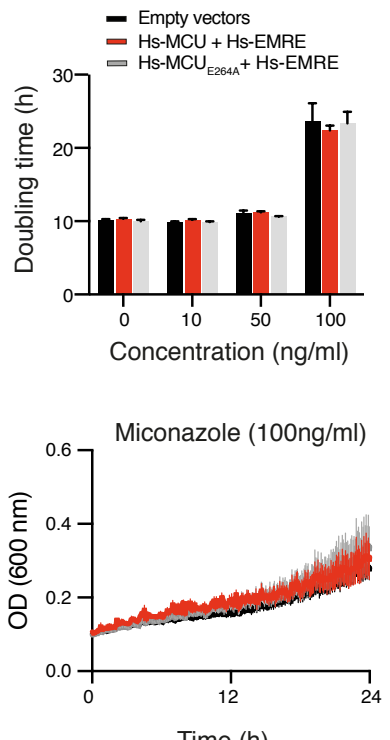

Time (h)
C

Amiodarone

D
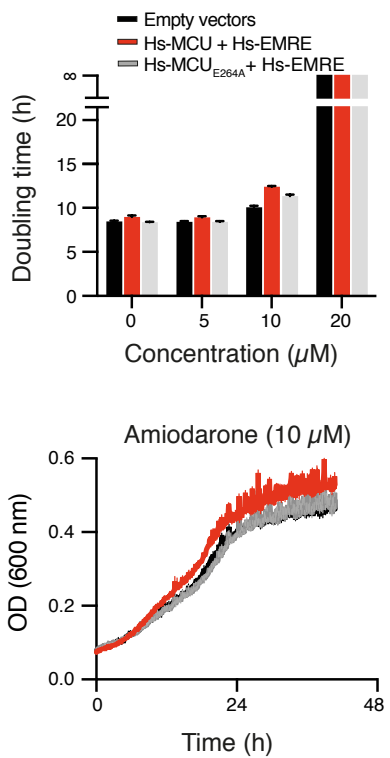

$\mathrm{ZnCl}_{2}$
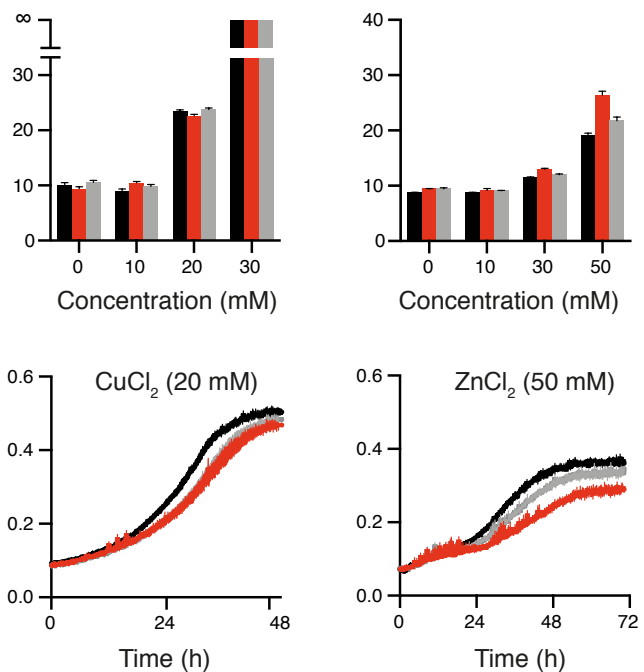

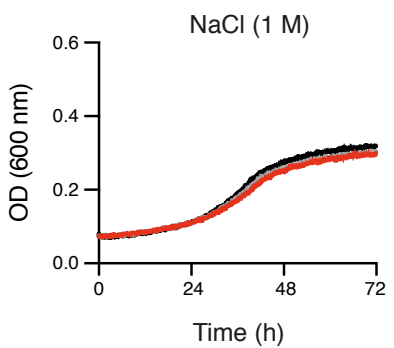

$\mathrm{FeCl}_{2}$

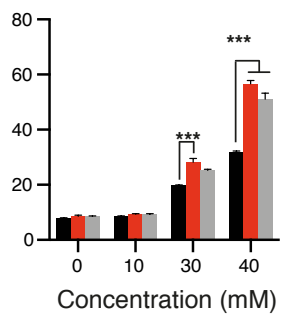

- Empty vectors

- $\mathrm{Hs}-\mathrm{MCU}+\mathrm{Hs}-\mathrm{EMRE}$

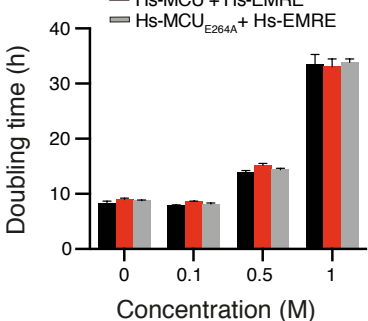

Concentration (M)

$\mathrm{NaCl}(1 \mathrm{M})$

$\mathrm{MnCl}_{2}$
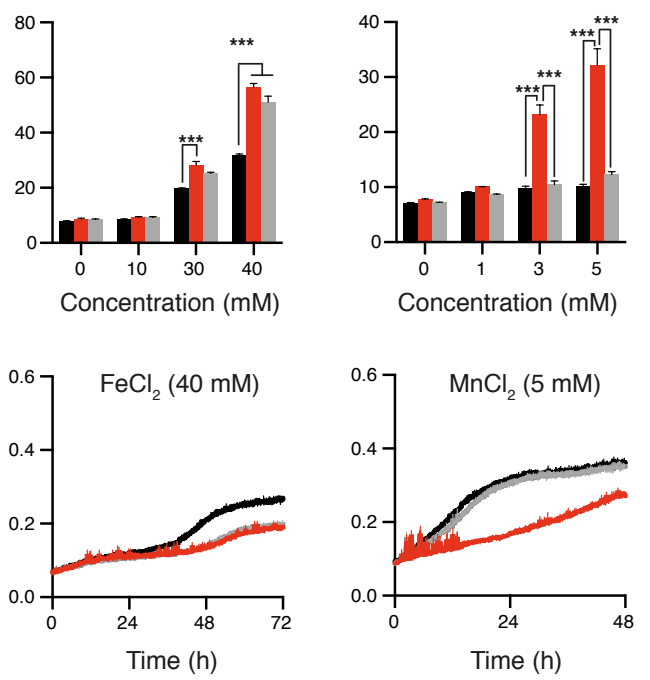

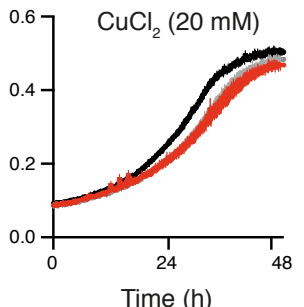

Time (h) 
Fjgure 4

$\mathrm{FeCl}_{2}$

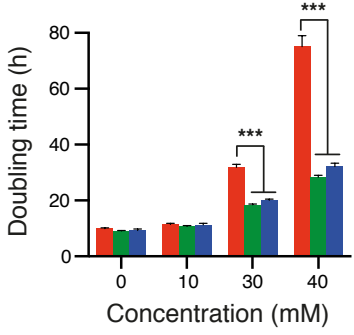

C

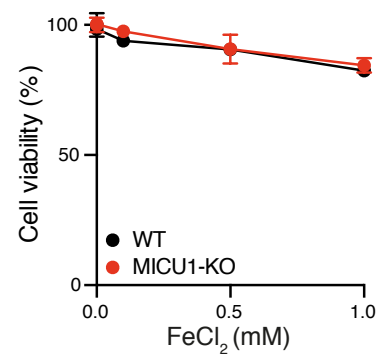

F

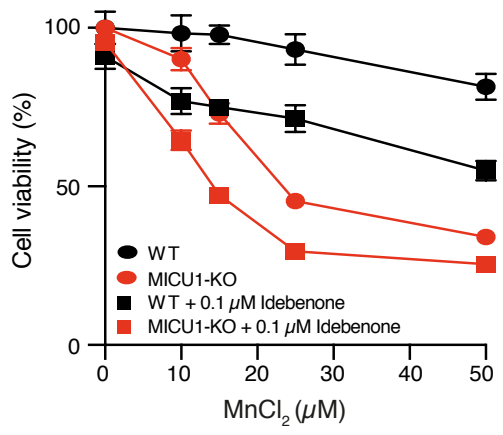

$\mathrm{FeCl}_{2}(40 \mathrm{mM})$

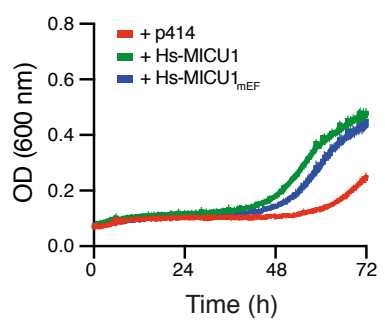

D

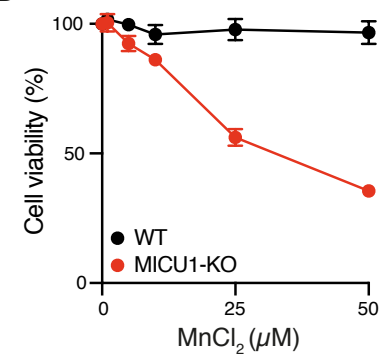

B

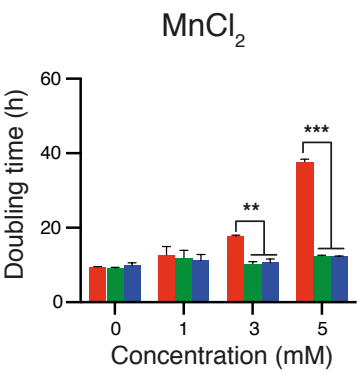

$\mathrm{MnCl}_{2}(5 \mathrm{mM})$

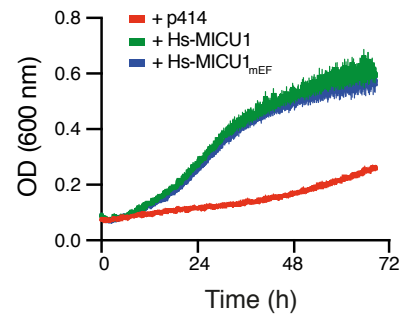

E

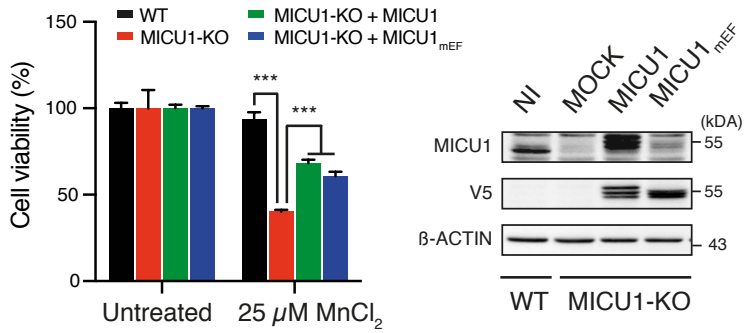

G

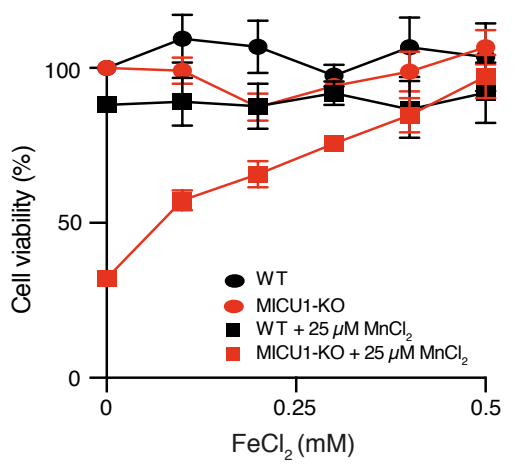

H

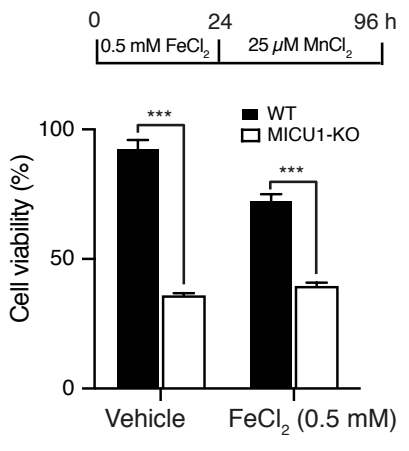




\section{SUPPLEMENTAL EXPERIMENTAL PROCEDURES}

\section{Phylogenetic Profiling of MICU1 and MCU}

Homologs of human MCU and MICU1 across 247 eukaryotes were retrieved from ProtPhylo (www.protphylo.org) (Cheng and Perocchi, 2015) using OrthoMCL with more than $0 \%$ match length and inflation index of 1.1 for orthology assignment. The percentage of amino acids match length was determined based on blastp. The phylogenetic tree of 247 eukaryotes was reconstructed using the phylogenetic tree generator (https://phylot.biobyte.de/) and visualized using iTOL (https://itol.embl.de/). The mitochondrial-targeting sequence (MTS) probability was determined with MitoProt (https://ihg.gsf.de/ihg/mitoprot.html).

\section{Protein Domains}

Protein sequences of Homo sapiens MCU (Hs-MCU, NP_612366.1) Neurospora crassa MCU (Nc-MCU, XP_959658.1), and Aspergillus fumigatus MCU (Af-MCU, XP_751795.1) were analyzed to predict MTS, DUF607 motif (Finn et al., 2016), coiled coil domains (CCD) (https://embnet.vital-it.ch/software/COILS_form.html), and transmembrane domains (TM) (TMHMM 2.0). Clustal Omega was used for proteins alignment and sequence similarities above $80 \%$ were color-coded with the Sequence Manipulation Suite.

\section{Plasmids and Reagents}

The lentiviral vector pLX304 was obtained from the Broad Institute's RNAi Consortium and used for expressing V5tagged cDNAs. Full-length, human wild-type EMRE (Hs-EMRE), MCU (Hs-MCU), MICU1 (Hs-MICU1) and their mutants (Hs-MCU $\mathrm{D} 261 \mathrm{~A}_{\mathrm{A}}, \mathrm{Hs}-\mathrm{MCU}_{\mathrm{E} 264 \mathrm{~A}}$, and Hs-MICU1 $\left.1_{\mathrm{mEF}}\right) \mathrm{cDNAs}$ without a stop codon were obtained from Addgene. Hs-MICU1 $1_{\mathrm{mEF}}$ contains two point mutations in the first (D231A, E242K) and the second EF-hand domains (D421A, E432K) as described in (Perocchi et al., 2010). Af-MCU and Nc-MCU with $\left({ }^{\mathrm{HsMTS}} \mathrm{Af}-\mathrm{MCU}\right.$ and $\left.{ }^{\mathrm{HsMTS}} \mathrm{Nc-MCU}\right)$ and without the N-terminal MTS of Hs-MCU (HsMTS, aminoacids 1-56) and without a stop codon were codon optimized for human expression and synthesized de novo in the PuC57 vector (GenScript). Cytosolic aequorin (cyt-AEQ) was kindly provided by Teresa Alonso and a mitochondria-targeted aequorin (mt-AEQ) was generated as previously described in (Arduino et al., 2017). Hs-EMRE, Hs-MCU, Hs-MICU1 and their mutants cDNAs were amplified by PCR using the following primers: fw-MCU, 5'-CCC TCT AGA ATG GCG GCC GCC GCA GGT AG-3'; rv-MCU, 5'GGG CTC GAG TTA ATC TTT TTC ACC AAT TTG TCG-3'; fw-MICU1, 5'-CCC GGA TCC ATG TTT CGT CTG AAC TCA CTT TC-3'; rv-MICU1, 5'-GGG CTC GAG TTA CTG TTT GGG TAA AGC GAA G-3'; fw-EMRE, 5'CCC GGA TCC ATG GCG TCC GGA GCG GCT CGC-3'; rv-EMRE, 5'-GGG CTC GAG TTA GTC ATC ATC ATC ATC ATC CTC-3'). PCR products were cloned into the yeast expression plasmids p423GPD (Hs-MCU, Hs$\mathrm{MCU}_{\mathrm{D} 261 \mathrm{~A}}, \mathrm{Hs}-\mathrm{MCU}_{\mathrm{E} 264 \mathrm{~A}}$ ), p414GPD (Hs-MICU1, Hs-MICU1 ${ }_{\mathrm{mEF}}$ ) and p425GPD (Hs-EMRE) (Mumberg et al., 1995). For expression in mammalian cells, cDNAs were first cloned into the pDONR221 Gateway vector (Thermo Fisher Scientific, 1253607) and subsequently transferred into the pLX304 vector according to manufacturer's instructions (Life Technologies). All chemicals were purchased from Sigma-Aldrich, unless specified.

\section{Cell Lines}

All mammalian cells were grown in high-glucose Dulbecco's modified Eagle's medium (DMEM) supplemented with $10 \% \mathrm{FBS}$ at $37^{\circ} \mathrm{C}$ and $5 \% \mathrm{CO}_{2}$. HeLa cells stably expressing mt-AEQ were generated as previously described (Arduino et al., 2017) and maintained in $100 \mu \mathrm{g} / \mathrm{ml}$ geneticin (Thermo Fisher Scientific, 10131027). Mt-AEQ HeLa cells stably overexpressing either a shRNA targeting Hs-MCU (shMCU; Sigma Aldrich, TRCN0000133861) or an empty vector (pLKO; Addgene, 8453) were generated as previously described (Baughman et al., 2011) and maintained in $2 \mu \mathrm{g} / \mathrm{mL}$ puromycin (Life Technologies, A11138) and $100 \mu \mathrm{g} / \mathrm{ml}$ geneticin. shMCU, mtAEQ HeLa cells stably overexpressing Hs-MCU, Nc-MCU, Af-MCU, ${ }^{\text {HsMTS }}$ Af-MCU and ${ }^{\mathrm{HsMTS}} \mathrm{Nc-MCU}$ from the pLX304 lentiviral vector were generated by transduction. Lentivirus production and infection were performed according to guidelines from the Broad RNAi Consortium and infected cell lines were selected with $10 \mu \mathrm{g} / \mathrm{mL}$ blasticidin (Life Technologies, R21001), $2 \mu \mathrm{g} / \mathrm{mL}$ puromycin, and $100 \mu \mathrm{g} / \mathrm{ml}$ geneticin. MICU1-knockout HEK-293 cells were kindly provided by Vamsi Mootha. MICU1-knockout HEK-293 cells stably overexpressing either wild-type or mutant Hs-MICU1 (Hs-MICU1 $1_{\mathrm{mEF}}$ ) from the pLX304 vector were generated by transduction and selected with $10 \mu \mathrm{g} / \mathrm{mL}$ blasticidin.

\section{Isolation and Analysis of Crude HeLa Mitochondria}

Cell lysates and crude mitochondria were prepared from cultured HeLa cells as previously described (Wettmarshausen and Perocchi, 2017) and immunoblotted with the following antibodies: anti-MCU (Sigma Aldrich, HPA01648), antiV5 (Life Technologies, R96025), and anti-ATP5A (Abcam, MS507).

Alkaline carbonate extraction from crude mitochondria was performed as described previously (Baughman et al., 2011). Mitochondrial soluble and membrane fractions were immunoblotted with anti-V5, anti-TIM23 (BD Bioscience, 611222), and anti-HSP60 (R\&D System, MAB1800) antibodies.

\section{Measurements of Mitochondrial Calcium Uptake in HeLa Cells}

Mitochondrial $\mathrm{Ca}^{2+}$ uptake was measured in mt-AEQ HeLa cells as previously described (Arduino et al., 2017). Briefly, HeLa cells stably expressing mt-AEQ were seeded in white 96-well plates at 25,000 cells/well in growth medium. After 24 hours, mt-AEQ was reconstituted with $2 \mu \mathrm{M}$ native coelenterazine (Abcam, ab145165) for 2 hours at $37^{\circ} \mathrm{C}$. Mt-AEQ-based measurements of $\mathrm{Ca}^{2+}$-dependent light kinetics were performed upon $100 \mu \mathrm{M}$ histamine 
bioRxiv preprint doi: https://doi.org/10.1101/371419; this version posted July 18, 2018. The copyright holder for this preprint (which was not certified by peer review) is the author/funder. All rights reserved. No reuse allowed without permission.

stimulation. Light emission was measured in a luminescence counter (MicroBeta2 LumiJET Microplate Counter, PerkinElmer) at $469 \mathrm{~nm}$ every $0.1 \mathrm{~s}$. At the end of each experiment, cells were lysed with a solution containing $0.1 \mathrm{mM}$ digitonin and $10 \mathrm{mM} \mathrm{CaCl}_{2}$ to release all the residual aequorin counts. Quantification of $\mathrm{mt}^{-\mathrm{Ca}^{2+}}$ concentrations was performed using the algorithm reported in (Bonora et al., 2013).

\section{Yeast Strains}

Yeast strains expressing mt-AEQ or cyt-AEQ were generated by transforming the yeast wild-type YPH499 strain and selecting transformants in glucose medium lacking uracil (Sikorski and Hieter, 1989). Yeast strains expressing different combinations of Hs-EMRE, Hs-MCU, Hs-MICU1 and their mutants were generated by simultaneously transforming the YPH499 strain with the respective plasmids and by selecting transformants on glucose medium lacking uracil (AEQ), histidine (Hs-MCU), leucine (Hs-EMRE), and tryptophan (Hs-MICU1) as selection markers. To test expression and mitochondrial localization of heterologous proteins, yeast were grown at $30^{\circ} \mathrm{C}$ in a selective lactate medium (SLAC) containing $8.5 \mathrm{~g} / \mathrm{L}$ yeast nitrogen base, $25 \mathrm{~g} / \mathrm{L}$ ammonium sulfate, $2 \%(\mathrm{v} / \mathrm{v})$ lactic acid, $0.1 \%$ glucose, supplemented with their respective selection markers at $\mathrm{pH} 5.5 / \mathrm{KOH}$. At an OD $\sim 0.8$ cells were harvested at $1000 \mathrm{~g}$ for $5 \mathrm{~min}$ at room temperature. The cell pellet was re-suspended in SHK buffer (0.6 M sorbitol, $20 \mathrm{mM} \mathrm{HEPES/KOH} \mathrm{pH}$ 7.2, $80 \mathrm{mM} \mathrm{KCl}$, and $1 \mathrm{mM}$ PMSF) and vortexed with glass beads (425-600 $\mu \mathrm{m}$ diameter) 5 times for $30 \mathrm{~s}$ with cooling down in between. This mix was centrifuged at $1000 \mathrm{~g}$ for $5 \mathrm{~min}$ at $4^{\circ} \mathrm{C}$ and the supernatant was further centrifuged at $20,000 \mathrm{~g}$ for $10 \mathrm{~min}$ at $4^{\circ} \mathrm{C}$. The resulting supernatant (cytosolic fraction) was precipitated with trichloroacetic acid. Both cytosolic and mitochondrial (pellet) fractions were directly resuspended in Laemmli buffer and separated under reducing conditions on 12 or 14\% SDS-PAGE gels. Immunoblotting was performed according to standard procedures using the following antibodies: anti-MCU (Sigma-Aldrich, HPA016480); anti-EMRE (Santa Cruz Biotechnology, sc86337); anti-MICU1 (Sigma Aldrich, HPA037480); anti-YME1 (Thermofisher/Novex, 459250); AEQ (Merck/Millipore, MAB4405).

\section{Measurements of Calcium Kinetics in Yeast}

In vivo analyses of cytosolic and mitochondrial $\mathrm{Ca}^{2+}$ kinetics in yeast cells were performed as described by (Groppi et al., 2011) with some modifications. Exponentially growing cells (OD $0.8, \sim 24 \times 10^{6}$ cells $/ \mathrm{mL}$ ) in S-LAC at $30^{\circ} \mathrm{C}$ were harvested by centrifugation at 3,500 $\mathrm{g}$ for $5 \mathrm{~min}$ at room temperature. The yeast cell pellet was washed three times with RT milliQ water and then resuspended in a nutrient-free buffer (NFB; $100 \mathrm{mM}$ Tris, $\mathrm{pH} 6.5$ ) at a density of $1 \times 10^{8}$ cells $/ \mathrm{mL}$. Cells were incubated for $1.5 \mathrm{~h}$ at room temperature, collected by centrifugation at $3,500 \mathrm{rpm}$ for $5 \mathrm{~min}$ and concentrated in the same buffer at a density of $25 \times 10^{8}$ cells $/ \mathrm{mL}$. The photoprotein aequorin was then reconstituted with $50 \mu \mathrm{M}$ native coelenterazine for $30 \mathrm{~min}$ at RT in the dark. Excess of coelenterazine was removed by three washes with NFB and the cell pellet was then resuspended at a final density of $5 \times 10^{8}$ cells $/ \mathrm{mL}$. About $0.5 \times 10^{8}$ cells $/$ well were placed in a white 96-well plate and $\mathrm{Ca}^{2+}$-dependent aequorin light response was measured upon addition of a spiking solution containing $\mathrm{CaCl}_{2}$ and glucose to a final concentration of $1 \mathrm{mM}$ and $100 \mathrm{mM}$, respectively, at $0.5 \mathrm{~s}$ intervals in a MicroBeta2 LumiJET Microplate Counter. At the end of each experiment, a lysis solution containing $5 \mathrm{mM}$ digitonin, $450 \mathrm{mM}$ EGTA, $100 \mathrm{mM}$ Tris $(\mathrm{pH} 6.5 / \mathrm{KOH})$ was added at a ratio pf $1: 5$ for $5 \mathrm{~min}$ at $37^{\circ} \mathrm{C}$ and light response was measured upon addition of $\mathrm{CaCl}_{2}$ to a final concentration of $100 \mathrm{mM}$ to release all the residual aequorin counts. Quantification of $\mathrm{mt}_{-} \mathrm{Ca}^{2+}$ concentrations was performed using the algorithm reported in (Bonora et al., 2013).

Measurements of $\mathrm{Ca}^{2+}$ uptake by mitochondria isolated from yeast strains expressing Hs-MICU1 were performed as it follows: crude mitochondria were isolated as described previously (Arduino et al., 2017) and $150 \mu \mathrm{g} / \mathrm{well} \mathrm{were}$ placed in a black 96-well plate and incubated in a buffer containing $0.6 \mathrm{M}$ sorbitol, $20 \mathrm{mM} \mathrm{HEPES,} 2 \mathrm{mM} \mathrm{MgCl}_{2}, 10 \mathrm{mM}$ $\mathrm{KH}_{2} \mathrm{PO}_{4}, 3 \mathrm{mM}$ glutamate, $3 \mathrm{mM}$ malate, $3 \mathrm{mM}$ succinate, $50 \mu \mathrm{M}$ EDTA, and $0.1 \mu \mathrm{M}$ Calcium Green-5N (Life technologies, $\mathrm{C} 3737)$ for $3 \mathrm{~min}$. $\mathrm{Ca}^{2+}$ uptake was initiated by $\mathrm{CaCl}_{2}$ injection $(100 \mu \mathrm{M}$ final concentration) and extramitochondrial free $\mathrm{Ca}^{2+}$ was monitored every $2 \mathrm{~s}$ at room temperature using a CLARIOstar microplate reader (BMG Labtech) at 506 and $531 \mathrm{~nm}$ excitation and emission, respectively. The MCU inhibitor Ru360 (10 $\mu \mathrm{M}$, final concentration) was used as a positive control.

\section{Yeast Growth Measurement}

Overnight yeast cultures grown at $30^{\circ} \mathrm{C}$ in S-LAC were diluted to an OD of $0.1\left(3 \times 10^{6}\right.$ cells $\left./ \mathrm{mL}\right)$ and then $0.3 \times 10^{6}$ cells/well were placed in a black, gas-permeable Lumox 96-well plate. The yeast suspension was measured at an absorbance of $600 \mathrm{~nm}$ and an interval of $340 \mathrm{~s}$ in the CLARIOstar microplate reader (BMG Labtech) for 48-72 hours with shaking at $30^{\circ} \mathrm{C}, 37^{\circ} \mathrm{C}$, or in presence of sterile solutions of sodium chloride ( $\left.\mathrm{NaCl}, 0.1-1 \mathrm{M}\right)$, copper (II) chloride $\left(\mathrm{CuCl}_{2}, 10-30 \mathrm{mM}\right)$, iron (II) chloride $\left(\mathrm{FeCl}_{2}, 10-40 \mathrm{mM}\right)$, manganese (II) chloride $\left(\mathrm{MnCl}_{2}, 1-5 \mathrm{mM}\right)$, strontium (II) chloride $\left(\mathrm{SrCl}_{2}, 10-50 \mathrm{mM}\right)$, zinc (II) chloride $\left(\mathrm{ZnCl}_{2}, 10-50 \mathrm{mM}\right)$, or antifungal drugs (miconazole, $10-100 \mathrm{ng} / \mathrm{ml}$; amoidarone, $5-20 \mu \mathrm{M}$ ). The average time taken by the yeast culture to double in the log-growth phase (doubling time) was calculated using the following equation:

Doubling time $=\frac{(\mathrm{T} f-\mathrm{T} i) * \log (2)}{\log (N f)-\log (N i)}$

where $\mathrm{T}$ is the time between the log-growth phase from $\mathrm{T} i$ to $\mathrm{T} f$ and $\mathrm{N}$ is the number of cells measured as an optical density at an absorbance of $600 \mathrm{~nm}$ at the time point $\mathrm{T} i(\mathrm{~N} i)$ and $\mathrm{T} f(\mathrm{~N} f)$.

\section{MTT Assay}

A colorimetric 3-(4,5-dimethylthiazol-2-yl)-2,5-diphenyltetrazolium bromide (MTT) metabolic activity assay was used to determine cell viability. HEK-293 cells were seeded at 50,000 cells/well in $1 \mathrm{~mL}$ of DMEM with high glucose and 
bioRxiv preprint doi: https://doi.org/10.1101/371419; this version posted July 18, 2018. The copyright holder for this preprint (which was not certified by peer review) is the author/funder. All rights reserved. No reuse allowed without permission.

$10 \%$ FBS in a transparent 24-well plate at $37{ }^{\circ} \mathrm{C}$ and $5 \% \mathrm{CO}_{2}$. After 24 hours, $\mathrm{FeCl}_{2}(0.1-1 \mathrm{mM})$ or $\mathrm{MnCl}_{2}(5-50 \mu \mathrm{M})$ were added to the well and the cells were incubated further for $48 \mathrm{~h}$. Afterwards, $500 \mu \mathrm{L}$ of medium was removed from the well, $50 \mu \mathrm{l}$ of MTT solution (Sigma Aldrich, M5655; $5 \mathrm{mg} / \mathrm{ml}$ in PBS) was added, and cells were incubated for $3 \mathrm{~h}$ at $37^{\circ} \mathrm{C}$. Finally, cells were lysed with $500 \mu \mathrm{l}$ of solubilization solution ( $1 \% \mathrm{SDS}$ and $0.1 \mathrm{M} \mathrm{HCl}$ in isopropanol) for 15 min at $37^{\circ} \mathrm{C}$ and absorbance was monitored in a CLARIOstar microplate reader (BMG Labtech) at $570 \mathrm{~nm}$.

\section{Data Analysis}

All data are represented as mean \pm SEM and the statistical details of experiments can be found in the figure legends. Normal distribution was tested by Shapiro-Wilk normality test. Differences between two datasets were evaluated by two-tailed unpaired Student's t test. Statistical tests between multiple datasets and conditions were carried out using one-way analysis of variance (ANOVA) followed by Tukey's or Dunnett's Multiple Comparison. Statistical analyses were performed using GraphPad Prism. 